جامعـة نيويورك أبـوظـبي

$\stackrel{\uplus}{i}$ NYU $\mid$ ABU DHABI

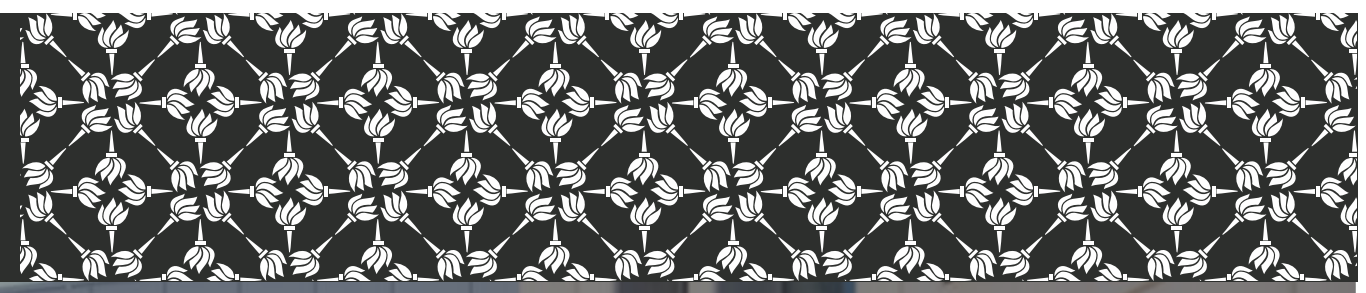

\title{
Electoral Administration in Fledgling Democracies: Experimental Evidence from Kenya
}

\author{
J. Andrew Harris, Catherine Kamindo, \\ Peter van der Windt
}

Working Paper \# 0036

January 2020 


\title{
Electoral Administration in Fledgling Democracies:
}

\section{Experimental Evidence from Kenya}

\author{
J. Andrew Harris (NYU Abu Dhabi)* \\ Catherine Kamindo (IEBC) \\ Peter van der Windt (NYU Abu Dhabi)
}

12 January 2020

\begin{abstract}
We examine the effects of national voter registration policies on voting patterns with a large-scale experimental study. Together with Kenya's electoral commission, we designed an experiment in which 1,674 communities were randomized to a status quo or treatment group, receiving civic education on voter registration, SMS reminders about registration opportunities, and/or local registration visits by election commission staff. We find little evidence that civic education improves registration. Local registration visits improve voter registration, a relationship that increases in poorer communities. Moreover, local registration increased electoral competition and vote preference diversity in down-ballot contests in the 2017 Kenyan elections. Our results suggest that status quo voter registration policies constrain political participation and competition, and that inexpensive policy changes may attenuate the effects of such constraints.
\end{abstract}

*Conditionally Accepted at The Journal of Politics. Corresponding author: andy.harris@nyu.edu. We thank Han Il Chang, Cornelius Lupao, Hannah Melville-Rea, and Cole Tanigawa-Lau for research support. We thank Jim Alt, Daniel Posner, Kerstin Fisk, Guy Grossman, Macartan Humphreys, Ryan Moore, Vincent Pons, and Kelly Zhang for comments. Thanks to participants attending presentations at EPSA, APSA, NYU Abu Dhabi, and Leuven University for feedback. This research could not have been carried out without the consistent support of Kenya's Independent Electoral and Boundaries Commission, particularly Andrew Limo, Decimah M'mayi, Michael Oyalo, William Kahindi, the Regional Election Coordinators, and the Constituency Election Coordinators. New York University - Abu Dhabi provided financial support. This study was reviewed by the New York University Institutional Review Board and granted exemption (039-2016). This study was pre-registered at http://egap.org/registration/2393. 


\section{Introduction}

How elections are organized shapes political participation and election outcomes. For instance, research in American politics demonstrates that policy choices like voter identification requirements, voting technology, and precinct design shape who can and does vote (Burden et al. 2014; Tomz and Van Houweling 2003). However, we know much less about how election administration affects political behavior in fledgling democracies, where scholars have focused more on issues like vote buying (e.g., Kramon 2016), political intimidation (e.g., Collier and Vicente 2012), ethnic mobilization (e.g., McCauley 2014), and electoral fraud (e.g., Ichino and Schundeln 2012). Yet the choices and policies that electoral commissions make about how to organize elections have the potential to affect whether and how citizens participate in elections. In this paper, we present the results of collaborative research with Kenya's electoral commission, the Independent Electoral and Boundaries Commission (IEBC), focusing on one key aspect of election administration: voter registration.

Understanding how voter registration policies affect citizen participation is important since, in many contexts, electoral commissions circumscribe which organizations can engage in registration-related activities. This is especially true in fledgling democracies, which often centralize policy decisions related to election administration. This reality sits in contrast to contexts like the United States, where election administration is decentralized, and third-party civic organizations play an important role in voter registration. ${ }^{1}$ Centralized election administration thus creates the possibility that existing policies systematically exclude some citizens. Thus, examining how citizens respond to departures from status quo policies provides insight into how existing policies may shape the electorate.

\footnotetext{
${ }^{1}$ In Appendix A, we present descriptive data on the nature and centralization of voter registration procedures across African countries, contrasting them with the relatively decentralized United States.
} 
Theoretically, election administration may shape citizen participation and electoral outcomes via three channels (Harder and Krosnick 2008): citizen ability (e.g., understanding eligibility requirements); motivation (e.g., social pressure or norms regarding participation); and difficulty (e.g., factors influencing the costs of participation). Election commissions may target these channels through decisions about where, how, and how often to register voters, as well as via their communication and education strategies. Geographic and neighborhood characteristics may moderate how such policies affect difficulty, motivation, and ability, and, in turn, participation.

To study how changes in voter registration policies affect voter registration, we designed a policy experiment with the IEBC to randomize information about and opportunities for voter registration. We developed three interventions, randomizing 1,674 polling stations into control and five treatment groups during November and December 2016. Control polling stations continued with the status quo, where citizens in the local community had to travel to a constituency election office to register to vote and received no additional information or prompts from the IEBC. The first intervention - localization reduced the cost, inconvenience, and difficulty of registration by sending IEBC staff with mobile registration equipment to register citizens. The second intervention - canvassing - involved IEBC civic educators providing citizens living near selected polling stations with information on registration, potentially improving a citizen's ability to participate by providing them with basic information about the benefits and requirements of registering to vote. The third intervention - SMS reminders - entailed sending mobile phone messages to existing registered voters asking them to remind their unregistered friends and acquaintances about registration opportunities, leveraging social relationships and pressure to improve registration. The content of these interventions represent potential alternative strategies that the electoral commission could use to register voters. As we discuss in detail below, our experimental design allows us to learn about the causal effect 
of these interventions and their combinations, as well as how they operate across different contexts. In addition, collaboration with the IEBC enabled access to administrative voter registration records for measuring the effects of these interventions.

This paper contributes in several ways to the burgeoning literature on how election administration shapes political behavior in fledgling democracies (De Kadt 2017; Neggers 2018; Ferree et al. 2018). First, we evince how changing centrally-organized and implemented voter registration policies to improve access to the franchise affects voter registration and election outcomes. Like Ichino and Schundeln (2012), we focus on the pre-election administrative process of voter registration. While that work examined registration-related fraud via random allocation of observers, our work shows how changing voter registration procedures affects voter registration patterns relative to the status quo. Consistent with research on costs of voter registration in Western contexts (e.g., Dyck and Gimpel 2005; Stein and Vonnahme 2008; McNulty, Dowling, and Ariotti 2009; H. E. Brady and McNulty 2011; Bhatti 2012; Braconnier, Dormagen, and Pons 2017) and the Harder and Krosnick (2008) theoretical framework, improving the accessibility of voting registration opportunities increases voter registration by about $2 \%$ over status quo polling stations. In contrast, observational evidence in Isaksson (2014) suggests that individual resources do little to explain variation in voter turnout, a result that may be explained by misreporting or social desirability bias in survey data (Kolstad and Wiig 2016; Adida et al. 2019).

Second, we find differences in effects by context. By combining satellite data with the spatial locations of polling stations, we blocked units on three prognostic covariates poverty, population density, and distance to the constituency election office - allowing us to efficiently estimate treatment effects across subgroups (Moore 2012). Similar to Nickerson (2015) and consistent with Harder and Krosnick (2008), we find strong differences 
by context, with higher-poverty units seeing the greatest increases in registration. Localization increases voter registration by approximately $4.4 \%$ in the poorest areas, relative to $0.7 \%$ in the richest areas. In addition, our results span across urban and rural areas a feature heretofore unexplored in the experimental literature - and show that distant, sparsely populated areas in particular benefit from reducing the difficulty of registration. These results suggest that some political inequalities relate to economic and geographical inequalities.

Third, we examine how impersonal SMS reminders of registration opportunities shape voter registration. Unlike previous work, we test the multiplicative nature of Harder and Krosnick (2008) directly. We find that when combined with localization, SMS reminders increase voter registration by $2.4 \%$ relative to the status quo, $20 \%$ more than localization alone. Without localization, SMS reminders have no effect. This contrasts with work showing the positive effects of SMS across a range of outcomes, including voter turnout (e.g., Dale and Strauss 2009; Malhotra et al. 2011; Marx, Pons, and Suri 2017), savings behavior (e.g., Karlan et al. 2016), and adherence to antiretroviral therapy (Pop-Eleches et al. 2011). However, our findings complement Bennion and Nickerson (2011), who find that SMS messaging increases voter registration in the United States, but only once an individual possesses a voter registration form. This is analogous to our findings in the (very different) Kenyan context: an SMS intervention is effective, but only once citizens are confronted with a registration opportunity.

Fourth, we ask how civic education efforts affect voter registration, finding that information alone does not increase voter registration. Specifically, we find near-zero effects for civic education, even when voter registration costs are reduced to zero. ${ }^{2}$ We

\footnotetext{
${ }^{2}$ In Appendix B, we give an overview of other studies that explore the impact of civic education on political behavior and knowledge, though these studies show little effect on behavioral outcomes like those studied here.
} 
know of two other studies that explore the impact of civic education on registration. Mvukiyehe and Samii (2017) find no evidence that civic education via town hall discussions improved registration in Liberia. Bratton et al. (1999), in contrast, examine multiple civic education programs in Zambia and find a positive impact on registration. Both studies rely on survey-based outcomes to measure voter registration, in contrast to the administrative data upon which this study builds.

Finally, we measure the effects of localization on Kenya's 2017 General Elections, which took place eight months after the interventions. Localization has a positive but insignificant effect on the total number of registered voters and votes cast at polling stations. In addition, localization decreased turnout rates, but this effect is indistinguishable from zero. This finding suggests that those registered during the experiment are less likely to vote. This result could be explained by a "double hurdle": localization affected the costs of registration, but not of getting to the polls on election day. We do find that local registration increased electoral competition and vote preference diversity in down-ballot contests.

In the next section we anchor this study in the Kenyan context, describing voter registration policies and barriers to registration. Section 3 discusses the interventions, data and empirical strategy. Section 4 presents the results. We conclude in Section 5.

\section{Electoral Administration and Barriers to Voter Registra- tion in Kenya}

Social tension, mistrust, and violence accompanied both the 2007 and 2013 General Elections in Kenya, which played out against a deeper background of ethnic politics and 
violence (Boone 2011; Kanyinga 2009; Mueller 2008; Cheeseman, Lynch, and Willis 2014). The 2017 General Elections - held eight months after the close of the interventions studied here - proved a continuation of these themes. Relative to problematic biometric voter registration in the 2013 elections, improved implementation translated into a six-fold decrease in the number of records missing biometric information and improvement in election-day electronic voter identification (Carter Center 2013; IEBC 2017; ELOG 2017). ${ }^{3}$ Despite these improvements, issues regarding results transmission and transparency led the Supreme Court to annul the presidential election. The nullification issued from qualitative non-compliance with electoral laws, rather than a demonstration that irregularities affected the electoral outcome. ${ }^{4}$ The fresh elections, held in October 2017, were largely boycotted by the opposition. In the election-related analyses below, we use data from the August elections, as the October data were incomplete due to the boycott.

Existing studies of voter registration focus on contexts where third-party registration is the norm, such as France (e.g., Braconnier, Dormagen, and Pons 2017) or the United States (e.g., Nickerson 2015). Third-party registration decentralizes voter registration policies by enabling outside groups to register voters (Herron and Smith 2013). In contrast, Kenya's IEBC is the sole body providing voter registration to citizens, an arrangement common in many developing countries. Specifically, the Constitution mandates that the IEBC provides continuous voter registration (CVR), giving citizens an opportunity to register throughout the year. In practice, this means that an IEBC staff member is available at a constituency election office to provide registration year-round. ${ }^{5}$

\footnotetext{
${ }^{3}$ According to a legally-mandated audit prior to the 2017 elections, Kenya's enrollment rate - the percentage of individuals registered divided by those eligible - stood at $78 \%$ by a measure defining eligibility as the estimated number of individuals possessing national identification documents. According to that report, this puts Kenya in 31st place among African countries in terms of citizen enrollment on the register.

${ }^{4}$ See Carter Center (2019) for a discussion of these legal debates.

${ }^{5}$ At the time of this experiment, Kenya had 290 constituencies, each of which had one constituency election office from which the IEBC organized election-related activities in that constituency.
} 
Anecdotal evidence and pre-experiment interviews with IEBC staff suggest that the CVR policy may generate political inequalities in several ways. First, the stationary approach to CVR puts the costs of voter registration on citizens. ${ }^{6}$ Traveling to register is costly, effectively barring poorer citizens from registering during CVR (IED 2007, xv). ${ }^{7}$ Furthermore, sparse population density may hinder information flows about, as well as citizen access to, voter registration opportunities when they do arise (IED 2002). Second, a lack of funding for mobile registration means that IEBC staff can only provide registration to a subset of relatively nearby communities. ${ }^{8}$ Third, political interests may sponsor IEBC voter registration drives in certain areas. This raises questions about the independence of registration opportunities, since politicians would theoretically be reticent to fund registration in areas where they have little political support.

Figure 1 complements this qualitative evidence with data. Using bivariate logistic regression, the figure shows that poverty rates, distance from the election office, and population sparsity are negatively related to voter registration at polling stations from March 16 to November 14, 2016 - the CVR period before the onset of the experiment. These data suggest that the status quo voter registration policy systematically excludes poorer, more remote, and more isolated polling stations from recruitment onto the voter register. Our blocked design (discussed below) explicitly incorporates these three factors to explore heterogeneous effects of the interventions.

Inequality in status quo voter registration policies appears to be a broader problem.

\footnotetext{
${ }^{6}$ In the counties studied here, the average constituency (the political unit with an IEBC registration office) serves 93 polling stations, with a minimum of 45 and a maximum of 213 polling stations. The average polling station is 20 kilometers from the registration office.

${ }^{7}$ We do not directly measure individual cost reductions in this paper. However, both discussions with IEBC staff and grey literature on election administration in Kenya suggest that cost is a key barrier to registration. For instance, IED (2007) (p. 12) reports: "Citizens sometimes must travel long distances to register, losing work hours and incurring heavy travel expenses."

${ }^{8}$ See IED (2007) (p. xii) and FIDA (2013). In pre-experiment interviews, constituency election coordinators consistently identified CVR as ineffective given a lack of budget to take registration "to the people."
} 
Figure 1: Voter Registration Decreases as Poverty, Distance and Population Sparseness Increase
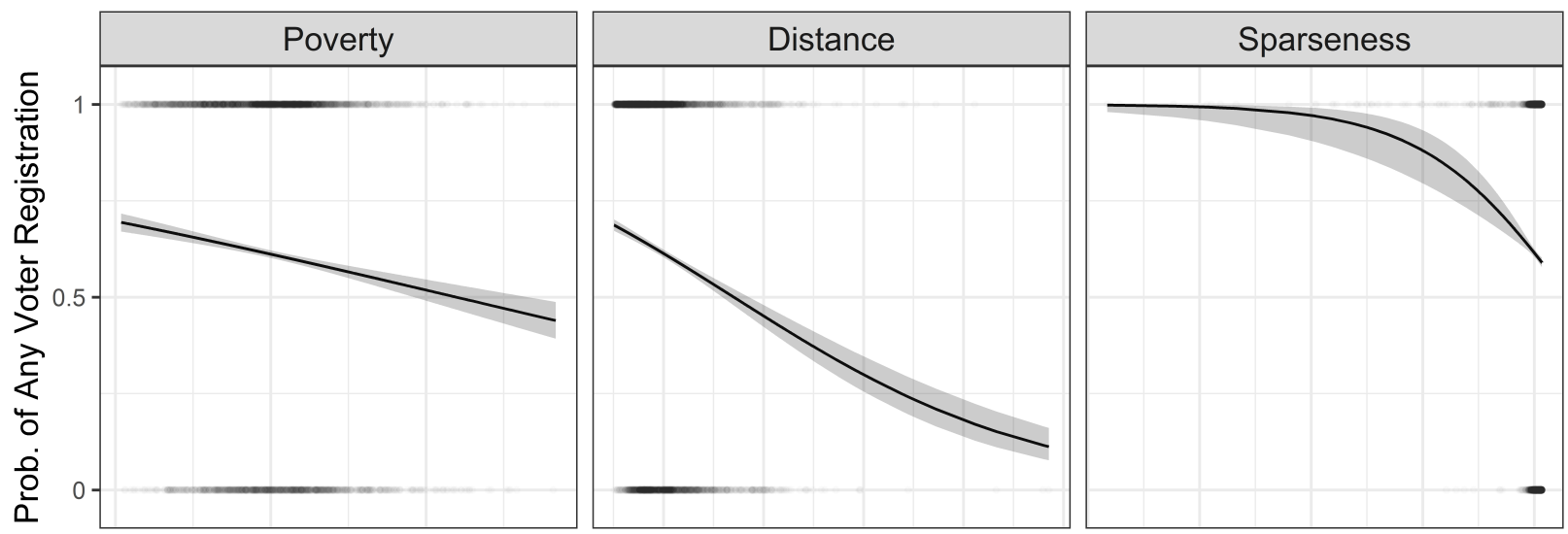

Standardized Predictor

Note: Bivariate logistic regression results, where the dependent variable is the predicted probability of at least one voter registering at a polling station during the period March 16 to November 14, 2016. Poverty, distance and population density are defined in Appendix C. Registration information from administrative data provided by the IEBC. Based on all 3,828 polling stations in the seven counties we study.

Bratton et al. (1999) discuss how geographic obstacles and questionable administrative independence led to registration inequality in Zambia's 1991 elections. ${ }^{9}$ Bratton and Lambright (2001) report similar issues with voter registration in Uganda's 2000 referendum. Elklit (1999) notes related issues in Nepal (1991), Kenya (1992), and South Africa (1999). Pallister (2017) provides evidence of problems with inclusivity in voter registration in Guatemala, El Salvador, and Nicaragua.

These problems are by no means limited to non-Western contexts. Writing on challenges of registering Black voters in the 1970's U.S. South, a period where third-party registration was relatively uncommon, Lewis and Allen (1972) find problems strikingly similar to Kenya's: "In most of the southern states, registration is conducted only at the county courthouse, requiring round-trip travel of 40 or 50 miles or more for residents in

\footnotetext{
${ }^{9}$ See Burnell (2002) for a similar discussion of Zambia's 2001 elections.
} 
outlying areas of rural counties. The lack of dispersed registration centers, the reluctance of election officials to appoint deputy registrars, and the absence of mobile registration stations also contribute to the suppression of initiative on the part of potential black registrants."

While the Kenyan context may be quite different than the United States, that does not necessarily mean that we should expect different behavioral responses. Individuals likely respond to decreased costs and additional information in similar ways, regardless of context. Rather, our contribution lies in a carefully planned experiment in both a different macro-context (i.e., where election administration is centralized), as well as a large variety of micro-contexts (via blocking). In the United States, cost-reductions can be implemented by any number of organizations seeking to register voters. In Kenya, the electoral commission's centralized control of registration means that they are uniquely responsible for shaping the registration costs of citizens. While we may see similar behavioral responses across contexts, the reasons for those changes and the counter-factuals that we can estimate via an experiment, are fundamentally different. Moreover, existing work on voter registration constraints focuses on urban contexts in high-income countries, whereas our results examine both rural and (relatively) urban areas settings in a low-to-middle income country (e.g., Nickerson 2015; Braconnier, Dormagen, and Pons 2017).

Understanding how status quo voter registration policies affect who can and cannot register to vote strikes at questions of democratic fairness and access germane to political processes worldwide. These questions are especially pressing in fledgling democracies, like Kenya, where often a single organization conducts voter registration in the presence of multiple barriers to political participation. In the next section, we describe a research design conceived to address such inequalities. 


\section{Experimental Design}

Given CVR's potential problems, we developed an experimental design with the IEBC to study how changes to the status quo may improve voter registration, particularly in poorer, more distant, and more sparsely populated communities. We study these problems in seven Kenyan counties, which were selected based on being sufficiently similar (by poverty, distance to registration office and population density) and the level of government support in the previous election. ${ }^{10}$ These counties contain 3,828 polling stations. We randomly selected 1,674 polling stations within these counties, following a strategy that minimized the chances of spillovers, and blocked on poverty, distance and population density. ${ }^{11}$

We define the units of analysis in this study as polling stations for several reasons. First, as in Nickerson (2015), there is no population register enabling us to identify and randomize across unregistered citizens. Nickerson (2015) addressed this problem by randomizing across streets. With no address or well-documented street system outside of large cities, this approach proved impossible. Polling stations provided a viable alternative. Second, the polling station is the smallest unit at which registration and election data are collected and available in Kenya. Third, polling stations are the natural randomization unit in this context, since registration policies are organized around polling stations and home registration is unavailable.

\footnotetext{
${ }^{10}$ County selection took place in collaboration with the IEBC to avoid perceptions of political bias. See Appendix $\mathrm{C}$ for further details.

${ }^{11}$ Details about county and polling station selection, and information about the selected counties, can be found in Appendix C. Ex post power calculations suggest that this study is well powered to observe even small effects (Appendix D).
} 


\subsection{The Interventions}

In addition to CVR, the IEBC implemented three types of interventions between 14 November 2016 and 23 December 2016. First, selected polling stations were visited for two days by IEBC staff with portable voter registration equipment, which captures a citizen's photograph, biometric information, and other required fields like gender, name, and date of birth. IEBC staff identified a location within approximately 250 meters of the selected polling station, setting up an IEBC banner and table for the registration equipment to register voters from 9am until $5 \mathrm{pm}$. Citizens in surrounding communities were able to register at this location. We call this intervention localization.

The second intervention involved canvassing. IEBC staff visited the communities surrounding the polling station for two days to provide basic education on the voter registration process, to discuss the importance of electoral participation, and to answer any remaining questions. IEBC staff also provided information on the practicalities of voter registration, including the location of the nearest registration opportunity. To maximize external validity, the IEBC used its standard training and implementation protocol for canvassing by IEBC field staff. The canvassing usually involved one-on-one householdlevel discussions that lasted around ten minutes. If the opportunity arose, impromptu discussions with groups of people lasted from ten to thirty minutes, depending on the number of questions raised. The IEBC instructed staff to canvass from 9am to 5pm, working outward from the polling station into the nearby communities. ${ }^{12}$

Third, the IEBC sent SMS messages to existing registered voters at a polling station. ${ }^{13}$ In Kenya, cellphone coverage and ownership is high. ${ }^{14}$ While citizens are not required

\footnotetext{
${ }^{12}$ The IEBC voter education manual can be found online: https:/ / www.iebc.or.ke/uploads/resources / pdQMe3WKeV.pdf. Accessed: August 7, 2019.

${ }^{13}$ The reason we target existing voters is because there is no phone registry listing unregistered citizens.

${ }^{14}$ Information from the nationally representative 2016 Afrobarometer survey, for example, indicates that $98 \%$ of enumeration areas have cellphone coverage, and $85 \%$ of respondents personally own a mobile phone.
} 
to provide a phone number upon registering to vote, many do. ${ }^{15}$ The message, which clearly identified the IEBC as the sender, asked citizens to encourage their unregistered friends and family to register and identified the nearest registration opportunity. Two SMS messages per person were sent over a two-day period. In total, the IEBC sent almost 300,000 messages via SMS. Because the SMS messages were sent only to already registered voters, this treatment could be considered conservative, relying on registered recipients sharing the information with an unregistered person. ${ }^{16}$

Were the interventions implemented? Project documents kept by IEBC staff report that all polling stations received their assigned treatment. Independent monitors made unannounced visits to a random ten percent of polling stations, finding, under reasonable assumptions given the mobility of canvassers, compliance of around $80 \%$ across treatment arms. ${ }^{17}$

\subsection{Random Assignment of the Interventions}

We randomly assigned treatment to polling stations following a two-by-three factorial design as in Table 1 below. In order to minimize the effect of spillovers, we first sampled 1,674 polling stations from the sampling frame of 3,828 polling stations. Our sampling algorithm ensured that polling stations were at least 1.5 kilometers apart. On average, sampled polling stations were separated by 2.4 kilometers. ${ }^{18}$ Each factorial cell contained 279

\footnotetext{
${ }^{15}$ Of the 338,988 previously registered voters in the sampled polling stations, 147,277 (43\%) of records listed a phone number, of which 143,704 (42\% of all records) were valid and included in the bulk SMS intervention. Note that registered voters providing their mobile numbers may be systematically different (e.g., more likely to share information) than those not sharing their contact information.

${ }^{16}$ The need for the information to be shared to be effective implies that the treatment effect is likely to differ across characteristics like a community's network structure. We did not measure these characteristics, but randomization implies that these should be balanced across treatment conditions.

${ }^{17}$ Appendix E discusses monitoring and compliance in more detail. In less than three percent of interventions, implementation dates differed from those assigned. Our analyses presented below use the assigned treatment dates, attenuating estimated treatment effects.

${ }^{18}$ Additional details related to randomization and treatment assignment can be found in Appendix C.
} 
polling stations. Pure control polling stations received no canvassing, SMS, or localization, representing the status quo CVR registration policy. For canvassing-only polling stations, citizens were provided with basic civic education and directions to the constituency election office for registration. For SMS-only polling stations, the text message reminded citizens to register to vote at the constituency office at any time. ${ }^{19}$ For localization-only polling stations, IEBC staff set up a portable registration site near the local polling station, enabling the local community to register on the spot without travelling to the constituency election office, thus reducing the distance (and travel costs) required to register. Polling stations assigned to both the localization and canvassing interventions received both treatments simultaneously on two consecutive days. During this intervention, canvassers directed citizens to the on-going local registration opportunity. For polling stations assigned localization and SMS interventions, the SMS was delivered for two consecutive days at $6 \mathrm{pm}$ the evening before the localization intervention began. ${ }^{20}$

Table 1: Polling stations by treatment status

\begin{tabular}{l|c|c|c} 
& Canvassing & SMS & Nothing \\
\hline Localization & 279 & 279 & 279 \\
\hline No Localization & 279 & 279 & 279 \\
\hline \multicolumn{2}{l}{ Note: Number of polling stations by treatment status. }
\end{tabular}

To measure treatment effects across different contexts, we grouped polling stations in blocks based on poverty, distance to the registration office, and population density. ${ }^{21}$ Blocking has several advantages. First, randomizing within blocks improves balance across treatments. Second, blocking allows efficient estimation of treatment effects within sub-groups (Duflo, Glennerster, and Kremer 2008).

\footnotetext{
${ }^{19}$ The SMS, translated from Kiswahili, read: "Thanks for being a registered voter! Those unregistered can register at IEBC office - (town/village). Please spread this message." The SMS was customized to identify the location of the closest IEBC office where registration occurs.

${ }^{20}$ The SMS, translated from Kiswahili, read: “Thank you for registering as a voter. IEBC will visit polling station [...] tomorrow to register voters. Please spread this message." The SMS was customized to indicate the location of the local registration opportunity.

${ }^{21}$ Specifically, we use multivariate continuous blocking as in Moore (2012).
} 
Finally, ethical concerns are inherent in any field experiment. Given that we worked in collaboration with the IEBC, potential registrants were unaware that the intervention was part of an experiment. Rather, it was viewed as part of the operations of the IEBC. This approach ensured that citizens would respond normally to the intervention. Relative to the status quo, the interventions pose little risk to citizens. Finally, the experiment included counties showing both government and opposition support, ensuring political impartiality.

\subsection{Data}

The target population is voting age individuals unregistered for the 2017 General Elections at the onset of the interventions. Collaboration with the IEBC provided access to detailed data on individual registration records. The data comprise individual-level records of a person's birth year, gender, cellphone number, the polling station where they wish to vote in the 2017 elections, and the day registration occurred. From these data, we generate outcome measures of registration at the polling station-day and polling station levels.

To measure the effects of the interventions on election day, we use publicly available data from the August 2017 Kenyan General Elections. Voters selected candidates for six different positions. Nation-wide, 8 candidates ran for president, 210 for governor, 256 for senator, 299 for county women representative, 1,893 for member of parliament, and 11,857 for ward representative. From the IEBC website, we collected turnout and vote outcomes at the polling station level for each election.

In addition, we used the spatial locations of polling stations to harvest spatial data on poverty rates, distance to the local constituency election office, and population density for each polling station. Appendix $C$ discusses these data. 


\section{Results}

In this section, we present experimental results in three steps. First, we examine the effects of the interventions on voter registration during the intervention period. Second, we examine heterogeneous treatment effects across sub-groups of poverty, distance, and population density. Third, we examine the downstream effects of the experiment on election day outcomes. ${ }^{22}$

\subsection{Proximate Impacts on Registration}

We first explore the proximate impact of the interventions on voter registration, focusing on the period from 14 November 2016, the onset of the interventions, to 6 January 2017, ten days after the last day of the interventions. In total, excluding weekends, the data include 66,560 polling station days across the six treatments. We focus on this period - which falls during normal CVR operations - to test how simple deviations from status quo policies affect voter registration.

While localization is likely to be effective only on the two days of the intervention when registration is present, information from canvassers or via SMS may motivate action in the days after treatment. To capture this, the (pre-registered) treatment variable defines the localization treatment as only the two days when the registration kit was at a randomly selected polling station. In contrast, the canvassing and SMS-only treatments are coded as the two intervention days plus a ten day "tail." The remaining polling station-days constitute the control condition. ${ }^{23}$

\footnotetext{
${ }^{22}$ In Appendix F, we show that the randomization procedure was successful in ensuring substantive balance between treatment groups.

${ }^{23}$ The ten-day tail and the asymmetry across interventions, although pre-registered and based on discussions with the IEBC, is admittedly ad hoc. In Appendix G, we present results across a range of specifications, which point to the same substantive conclusions. We find no evidence for additional registrations beyond
} 
During the intervention period, polling station days assigned to the status quo condition saw few individuals register: approximately 1 individual every 22.7 days $(0.044$ individuals per polling station per day). In total, of the 66,560 polling station days assigned to the status quo condition, only 2,568 (3.86\%) experienced nonzero registrations, $0.01 \%$ of 2013 registered voters. ${ }^{24}$ These low numbers are consistent with prior CVR results (IREC 2008).

Table 2 presents the estimated treatment effects of the interventions, using a variety of model specifications, which point to similar substantive conclusions. Column 1 presents results from regressing the total number of individuals registered on the six treatment conditions at the polling station-day level. Column 2 adds block, polling station and day fixed effects. ${ }^{25}$ Column 3 adds controls for poverty, distance from the registration office, and population density, and weights by the inverse of the polling station-specific inclusion probability to estimate population average treatment effects.

To better interpret effect sizes, column 4 measures the outcome as the number of registered individuals at a polling station day divided by the total number of registered individuals at that polling station in $2013 .{ }^{26}$ Coefficients in this column can be interpreted as the effect of a single day of intervention on voters registered on that day, as a percentage of 2013 registration.

Finally, in column 5, we collapse the temporal element of our data to the polling station level. Summing across the entire intervention period decreases statistical power the tail of the original definition.

${ }^{24}$ In Appendix $\mathrm{H}$, we present summary information at baseline.

${ }^{25}$ This is our pre-registered equation: $y_{i t}=\alpha+\beta_{1}$ Canvassing $_{i t}+\beta_{2}$ SMS $_{i t}+\beta_{3}$ Local $_{i t}+\beta_{4}$ Local $_{i t} \times$ Canvassing $_{i t}+\beta_{5}$ Local $_{i t} \times \mathrm{SMS}_{i t}+\psi_{b}+\gamma_{i}+\phi_{w}+\epsilon_{i t}$ where $y_{i t}$ is the total number of voters registered at polling station $i$ on day $t$. Local, Canvassing and SMS are dummy variables and equal to one if polling station $i$ received the respective treatment on day $t$, and zero otherwise. $\psi_{b}$ is a block fixed effect; $\gamma_{i}$ is a polling station fixed effect; $\phi_{w}$ is a vector indicating the day of the week in order to account for weekly cyclical patterns that might affect registration, such as market days; $\epsilon_{i t}$ is an error term clustered at the polling station.

${ }^{26}$ Note that we are not able to measure the number of individuals registered by the eligible voting age population, because these data are not available at the polling station level. 
but simplifies the interpretation of results and takes away the possibility of incorrectly defining the treatment. ${ }^{27}$ This column reports the effect of the two day intervention on total registrations at the polling station during the entire intervention period as a share of 2013 registered voters.

Table 2: Impact of Interventions on Voter Registration

\begin{tabular}{lccccc}
\hline \hline & $\begin{array}{c}\text { \# Regs } \\
(1)\end{array}$ & $\begin{array}{c}\text { \# Regs } \\
(2)\end{array}$ & $\begin{array}{c}\text { \# Regs } \\
(3)\end{array}$ & $\begin{array}{c}\text { \# Regs by 2013 } \\
(4)\end{array}$ & $\begin{array}{c}\text { \# Regs by } 2013 \\
(5)\end{array}$ \\
\hline Canvassing effect & $0.052^{* * *}$ & $0.059^{* * *}$ & $0.055^{* * *}$ & $0.0003^{* *}$ & 0.001 \\
& $(0.018)$ & $(0.019)$ & $(0.018)$ & $(0.0001)$ & $(0.003)$ \\
SMS effect & 0.001 & -0.002 & -0.003 & -0.00001 & -0.001 \\
& $(0.008)$ & $(0.010)$ & $(0.011)$ & $(0.00003)$ & $(0.003)$ \\
Localization effect & $3.170^{* * *}$ & $3.163^{* * *}$ & $2.928^{* * *}$ & $0.010^{* * *}$ & $0.020^{* * *}$ \\
& $(0.301)$ & $(0.305)$ & $(0.270)$ & $(0.002)$ & $(0.003)$ \\
Localization+Canvassing effect & $3.630^{* * *}$ & $3.627^{* * *}$ & $3.601^{* * *}$ & $0.011^{* * *}$ & $0.020^{* * *}$ \\
& $(0.263)$ & $(0.266)$ & $(0.265)$ & $(0.001)$ & $(0.003)$ \\
Localization+SMS effect & $4.705^{* * *}$ & $4.701^{* * *}$ & $4.093^{* * *}$ & $0.012^{* * *}$ & $0.024^{* * *}$ \\
& $(0.387)$ & $(0.391)$ & $(0.316)$ & $(0.001)$ & $(0.003)$ \\
\hline Control average & 0.0437 & 0.0437 & 0.0437 & $1 \mathrm{e}-04$ & 0.0043 \\
Level of analysis & PS day & PS day & PS day & PS day & PS \\
Pre-registered & No & Yes & No & No & No \\
Block FE & No & Yes & Yes & Yes & Yes \\
Polling Station FE & No & Yes & Yes & Yes & No \\
Day FE & No & Yes & Yes & Yes & No \\
Controls & No & No & Yes & Yes & Yes \\
Weights & No & No & Yes & Yes & Yes \\
Observations & 66,880 & 66,880 & 66,880 & 66,720 & 1,668 \\
$\mathrm{R}^{2}$ & 0.222 & 0.254 & 0.261 & 0.171 & 0.350 \\
\hline \hline
\end{tabular}

Note: ${ }^{*} \mathrm{p}<0.1{ }^{* *} \mathrm{p}<0.05 ;{ }^{* * *} \mathrm{p}<0.01$. Clustered, robust standard errors in parentheses (columns 1 to 4 ). Unit of analysis for columns 1 to 3 is the polling-station day and the outcome is the absolute number of registered voters. Columns 4 and 5 divide the outcome by the number of registered voters in 2013, measured at the polling station-day level and polling station-level, respectively. For Localization, Localization+Canvassing and Localization+SMS, treatment are the two days at which the intervention took place. For Canvassing-only and SMS-only, treatment are those two days at which the intervention took place plus the ten following days. The remaining days plus polling station days assigned to the control areas, are status quo. The full experimental sample involved 1,674 polling stations, based on data provided by IEBC in 2016. However, six polling stations were dropped due to operational reasons (e.g., stations were retired from service for the 2017 elections or had zero registered voters in 2013). This leaves us with 66,720 $(1,668)$ observations in column $4(5)$.

Table 2 demonstrates that localization drives most registration increases. This suggests

\footnotetext{
${ }^{27}$ The polling station-level equation is: $y_{i}=\alpha+\beta_{1}$ Canvassing $_{i}+\beta_{2}$ SMS $_{i}+\beta_{3}$ Local $_{i}+\beta_{4}$ Local $_{i} \times$ Canvassing $_{i}+\beta_{5}$ Local $_{i} \times \mathrm{SMS}_{i}+\psi_{b}+\epsilon_{i}$. This equation is identical to the equation above, except for dropping weekday indicator variables and polling station fixed effects.
} 
that costs and convenience, not information, constitute the main constraint to registration. For ease of interpretation, we focus on column 5 , the most conservative estimates. ${ }^{28}$ We find little evidence that SMS or canvassing substantively increased the number of registrations compared to control communities. ${ }^{29}$ In contrast, localization increased voter registration as a share of 2013 voters by 2 percent. While polling stations assigned to the status quo (CVR) saw an increase in registered voters by 0.4 percent, polling stations that received localization saw an increase of 2 percent. $^{30}$ The effect is substantial and statistically significant $(\mathrm{p}<0.01)$.

The combination of localization and SMS is especially effective at increasing registration, leading to a 2.4 percent increase relative to the status quo. The difference in voter registration between areas with localization and SMS and localization (or localization plus canvassing) is statistically significant $(\mathrm{p}<0.01) .{ }^{31}$ These results suggest that SMS reminders of a local registration opportunity provide one cost-effective way to increase voter registration. However, information only appears to work in the presence of difficulty-reducing interventions like localization.

\footnotetext{
${ }^{28}$ There are some differences in the effect of canvassing between columns 1 to 4 and that in column 5 . In columns 1 to 4 , the effect of canvassing is statistically significant but substantively quite small, while that in column 5 is indistinguishable from zero. Similarly, columns 1 to 4 suggest a small increase in registration due to canvassing, either in isolation or combination with localization. However, these effects are minor relative to the difference between interventions with and without localization.

${ }^{29}$ In Appendix B, we give a summary of other studies exploring the impact of civic education interventions. First, there is much variation in the type of interventions studied. Second, the average participant's length of exposure in the intervention we study here is shorter than the interventions explored by other studies. Perhaps a longer treatment or different content may have increased registration. We discuss this further in the conclusion.

${ }^{30}$ By election day, we find that the intervention leads to a positive but insignificant increase in total registered voters at the polling station level (see Section 4.3).

${ }^{31}$ In Appendix I, we show that all intervention effects, with the exception of localization versus localization plus canvassing, are statistically distinguishable from from each other $(\mathrm{p}<0.05)$.
} 


\subsection{Effect Heterogeneity in Poverty, Distance, and Population Density}

Section 2 revealed considerable heterogeneity across polling stations in poverty, distance, and population density. Previous studies in the developed world have found that social economic status is positively correlated with political participation and interest in general (e.g. Verba, Scholzman, and Brady 1995), and voter registration in particular (Nickerson 2015). Distance from the polling place similarly hinders participation (Dyck and Gimpel 2005; H. E. Brady and McNulty 2011). Our blocked design makes it possible to examine the heterogeneous effects of the interventions on registration as a function of levels of poverty, distance to registration opportunities, and population density.

Figure 2's top row shows the results of column 5 of Table 2 for different levels of poverty. We calculate the average level of poverty for each of the 279 blocks, and then subset the blocks into five equally sized groups based on these block-level means. The blocks are organized from left to right increasing in poverty. The leftmost panel presents the results from the richest quintile of blocks, while the rightmost panel focuses on the poorest quintile. We highlight two main results. First, localization has a positive impact in all five sub-groups. Second, the impact of localization is higher in poorer areas. The impact of localization is six times as large in the poorest quintile relative to the richest quintile $(4.39 \%$ vs. $0.73 \%)$. This suggests that poorer communities in particular benefit from localization. ${ }^{32}$

We find similar dynamics for distance and population density. The center row in Figure 2 presents the effects of the interventions by quintiles of distance to the registration office, where the leftmost panel presents the results focusing on the quintile of blocks closest to the registration office, while the rightmost panel focuses on those farthest away.

\footnotetext{
${ }^{32}$ These results contrast with De Kadt (2017), who shows that the expansion of polling stations in South Africa benefited richer citizens. We discuss this difference in more detail below.
} 
Similar to poverty, localization has a positive effect across all panels. Moreover, the effect of localization in the most distant polling stations is considerably larger as that in more proximate polling stations ( $2.26 \%$ vs. $1.59 \%)$.

Finally, the bottom row of Figure 2 presents the results by quintiles of population density. The leftmost panel presents results for the densest quintile of blocks, while the rightmost panel focuses on the sparsest quintile. Again, localization has a positive effect across all panels. Furthermore, the effect in sparsely populated areas is almost six times larger than that in densely populated areas ( $5.34 \%$ vs. $0.99 \%)$.

These results suggest that registration is a much bigger problem among the poor, as well as those living in distant and sparsely populated areas. Changes in status quo registration policy are thus likely to have the most significant impact on citizens in such communities. 
Figure 2: Results by Poverty, Distance and Population Density
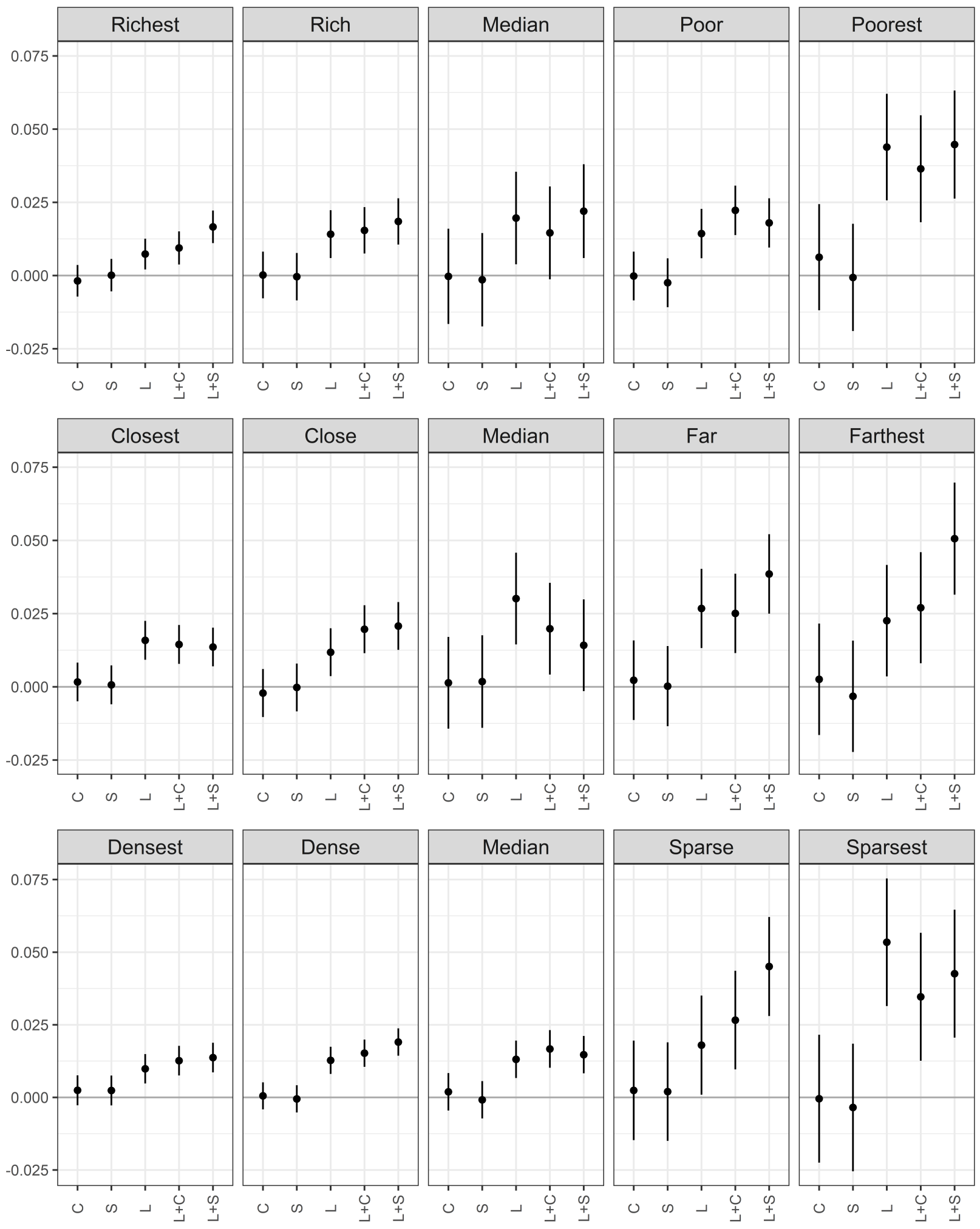

Note: Bars indicate 95\% confidence intervals. Dependent variable is the number of registered voters at a polling station during the intervention period divided by the total number of registered voters at that polling station in 2013. For the top row we calculate the average level of poverty for each of the 279 blocks, and then subset the blocks into five equally sized groups based on these block-level means. We do the same for distance (center row) and density (bottom row). The blocks are organized from left to right increasing in poverty (top), distance (center row) and density (bottom row). 


\subsection{Downstream Effects on Registration, Turnout, and Vote Choice}

While localization has positive effects during the intervention period, what are the downstream effects of localization on election day? ${ }^{33}$ Increases in voter registration may increase turnout (Nickerson 2015). The interventions may also change the distribution of candidate support at a polling station by registering citizens with different preferences (De Kadt 2017). On the other hand, the effects presented thus far may be due to temporal displacement, i.e., individuals that registered to vote due to the interventions would have registered later in the intervention's absence.

Our intervention period represents a sliver of the entire five-year cycle of voter registration. Thus, the two-day interventions may not be of sufficient magnitude to affect election day outcomes. To address this, we combine polling stations receiving any localization - which induced virtually all of the total estimated effects during the intervention period - and compare them to polling stations that did not receive localization.

Figure 3 examines the effect of localization across all six races on election day outcomes: total registered voters, total turnout, turnout rate, vote margin, and preference diversity. Bars indicate 95\% confidence intervals, and the dependent variables are standardized to enable comparison across outcomes. First, we explore the overall number of registered voters for the 2017 election relative to that in 2013. Kenyans have to register only once and the effects are thus the same across races. Relative to control, localization increased 2017 registration relative to 2013 by $1.4 \%$ or 0.052 standard deviations. Thus, localization temporally displaced the registration decision of some voters, causing them to register earlier than they otherwise would have. Relative to the $2 \%$ effect at the end of our intervention period, the estimated election day effect of localization becomes $1.4 \%$.

\footnotetext{
${ }^{33}$ This experiment was not originally designed to detect downstream effects; thus, the analyses in this section are not pre-registered.
} 
This implies that $0.6 \%$ of the overall increase consists of individuals who would have registered in the absence of the intervention. While these findings are consonant with our expectations, they are not statistically significant.

Second, we explore voter turnout and turnout rates. Because Kenyans vote for all six races at the same time (using separate ballots), the effects are again very similar across races. On average, localization increased voter turnout by around 0.04 standard deviations relative to control polling stations. However, localization depressed turnout rates, measured as the number of votes cast divided by the number of registered voters in 2017 , by an average of 0.03 standard deviations. This result is consistent with the notion of a "double hurdle": localization relaxed constraints related to registration but not voting. Again, these results remain statistically insignificant.

Finally, we explore the impact of localization on vote margins and vote fractionalization. ${ }^{34}$ We find that localization led to a $2.8 \%$ (0.09 standard deviation) decrease in vote margins at the polling station level in the women's representative race $(p<0.01)$. This suggests that improving access to voter registration may increase political competition. Moreover, localization increased the diversity of expressed political preferences in the women's representative race by $0.014(\mathrm{p}<0.05)$ or 0.06 standard deviations. In the context of a tight two candidate race, this is equivalent to adding a third party candidate receiving 1.4 percent of the vote. The increase in vote fractionalization (and decrease in vote margins) means that localization increases political competition by recruiting new voters that are more likely to support secondary candidates than voters recruited via status quo processes. ${ }^{35}$ The statistically significant findings, however, are confined to the women's representative race. On the one hand, this makes theoretical sense: if the interventions

\footnotetext{
${ }^{34}$ Vote margin is measured as the percentage of votes for the winner minus the percentage of the votes for the second place candidate. Vote fractionalization is measured as one minus the sum of candidates' squared vote shares.

${ }^{35}$ As a reviewer noted, this may not necessarily be a normative good if it leads to more spoiler candidates.
} 
were to have any effect on the kind of preferences recruited to the voter register, it would likely be preferences over newer, less-salient, and down-ballot contests like the women's representative and senator. Both of these contests exhibit similar point estimates for vote margin and preference diversity. On the other hand, Figure 3 presents 30 estimates and one would expect, given the $95 \%$ confidence intervals, just under two of thirty tests to be significant, simply by chance. Thus, we remain somewhat circumspect on the substantive interpretation of the effects of localization on the election.

Figure 3: Downstream Effects of Localization on Voter Registration and Election Outcomes

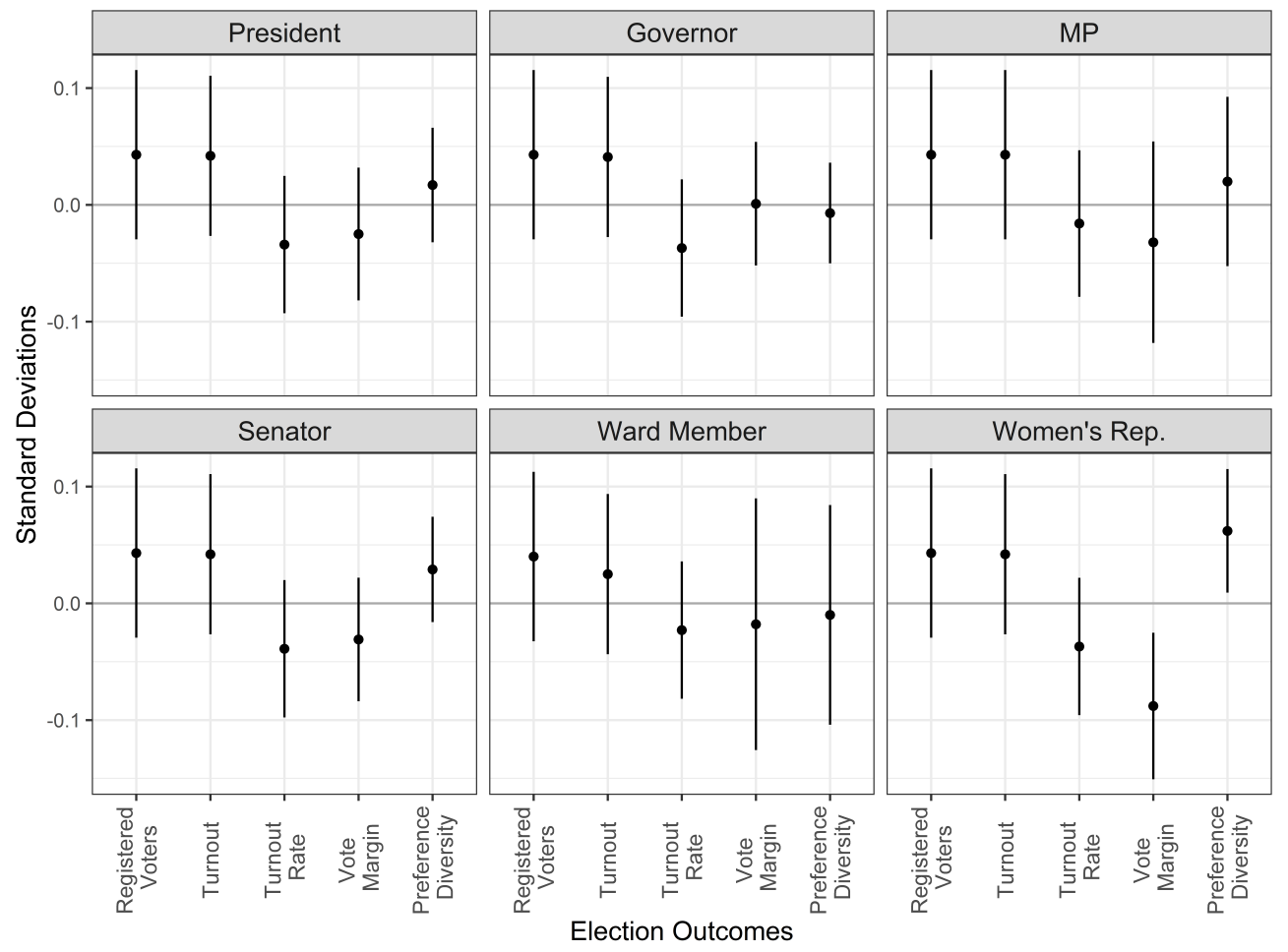

Note: Effect of localization across all six August 2017 races on total registered voters, total turnout, turnout rate, vote margin, and preference diversity. Bars indicate $95 \%$ confidence intervals. Dependent variables are standardized to enable comparison across outcomes. Turnout rate is the number of votes divided by number of registered voters. Preference diversity is measured using fractionalization. 


\section{Discussion and Conclusion}

In this paper, we explore two questions related to election administration in fledgling democracies. First, do status quo policies for voter registration create systematic barriers to political participation? Second, if such barriers exist, how can they be overcome? We partnered with the Kenyan electoral commission to implement a large-scale experiment providing citizens with information about and access to voter registration to address these questions. We find little evidence that providing knowledge or reminders about registration encourages participation. Rather, we find that material costs related to registration functionally disenfranchise poorer, more distant, and more sparsely populated communities. Our study is perhaps most similar in spirit to Nickerson (2015), who finds that average registration increases by about $4.4 \%$ in response to a door-to-door registration drive. The magnitude we report is approximately half of this, although the effect size varies by context. The poorest subgroup in Nickerson (2015) reported a 7.3\% increase in registration, relative to a $4.4 \%$ effect in the poorest block in this study. Interestingly, Nickerson (2015) (p. 95) notes that the average effect of $4.4 \%$ arises "in the contemporary [United States] setting where voter registration is moderately easy." This raises the question as to whether the relatively modest results we observe (relative to Nickerson 2015) might be driven by the more onerous nature of Kenya's voter registration process and the environment in which it is carried out. ${ }^{36}$

Our results have important implications for electoral administration and democracy promotion in the developing world. While there is limited evidence that civic education improves registration or turnout, existing research in lower-income contexts does find

\footnotetext{
${ }^{36}$ Appendix J reviews related work on voter registration and GOTV experiments, and discusses the magnitude of our results relative to the broader literature. It is also worth noting that, in contrast to Nickerson (2015), the localization intervention did not use door-to-door registration. Localization thus decreased the cost of the intervention, but did not bring it to zero.
} 
that civic education may improve knowledge and other forms of political participation. ${ }^{37}$ Finkel, Horowitz, and Rojo-Mendoza (2012), for instance, find that in-person civic education programs in Kenya led to increases in a broad measure of local - but not national - political participation. Similarly, Mvukiyehe and Samii (2017) find positive effects of experimentally-allocated civic education interventions on both self-reported and behavioral measures of participation in Sierra Leone. Bratton et al. (1999) find similar results in Zambia. We contribute to this body of work by juxtaposing the benefits of civic education with alternative interventions on voter registration, finding that the largest benefits to voter registration may lie in changing convenience and cost, not providing civic education. One implication is that election administrators and donors should focus their efforts on cost-reducing measures like the localization of registration examined in our study. Doing so may increase political participation and, as a result, electoral competition.

Moreover, the localization results complement existing work showing how accessibility affects political participation (McNulty, Dowling, and Ariotti 2009; H. E. Brady and McNulty 2011; Bhatti 2012). Our results present experimental evidence that existing voter registration policies may functionally disenfranchise certain populations in the developing world by making it more difficult for some citizens to register. While this effect may not be intentional, a lack of viable registration options disadvantages citizens living in poorer, more remote, and more sparsely-populated areas. In some respects, these results contrast with the careful observational analysis in De Kadt (2017), which finds a three to five percent increase in voter turnout across 15 years due to the expansion of polling stations in South Africa. Citizens in higher socio-economic groups were particularly responsive to changes in access, in apparent contradiction to our results where citizens from poorer areas were more responsive. Two differing aspects of the studies may explain this seeming disparity.

\footnotetext{
${ }^{37}$ See Appendix B for a careful exposition of other civic education studies. A robust literature from highincome countries suggests that face-to-face canvassing and voter education cause increased participation in those contexts as well (e.g., Braconnier, Dormagen, and Pons 2017; Green and Gerber 2015).
} 
First, De Kadt (2017) studies how the addition of new polling stations generates participation, whereas our work examines random localization at existing polling stations. Thus, while we can estimate an average treatment effect representing a deviation from an existing policy, the estimates in De Kadt (2017) represent an estimate of an expansion policy which may serve urban - and richer - citizens with greater demand for additional polling station capacity. Second, the interventions tested here focus on unregistered citizens near existing polling stations, while the De Kadt (2017) study engages with a different population entirely: both registered subpopulations whose access was eased, as well as unregistered populations engaged by newly established stations. As a result of these differences, we are hesitant to suggest that our results contradict those in De Kadt (2017), but rather speak to the complicated nature of election administration as it relates to political behavior.

One objection to improving access to registration is that it is not cost effective. Localization, however, is relatively cost-effective. An average cost of $\$ 25$ per localization day translates into a cost per registration of $\$ 8.33$ (average) or $\$ 3.57$ (highest poverty block). This compares favorably to status quo costs per registered voter of US\$13.74 in an election year, with non-election years significantly higher due to lower registration numbers but identical fixed costs (IREC 2008, 44). Adding SMS to localization improves this cost comparison, given the relative effectiveness and low cost of SMS bulk messaging relative to canvassing, ${ }^{38}$ bringing the electoral commission's registration costs well within sustainable per registration cost targets (IFES 2005, 173). ${ }^{39}$ Moreover, the estimates assume hiring additional IEBC personnel; implementation with existing employees carrying out regular localization may drive costs even lower.

This study is not without limitations. Perhaps most pressing, the present study

\footnotetext{
${ }^{38}$ For the cost of one canvasser sent to a polling station, we could send over 2,000 SMS messages, which would cover almost four average sized polling stations.

${ }^{39}$ In addition, these estimates are likely an upper bound, given that our intention-to-treat analysis probably underestimates the actual effect of localization.
} 
examines the effect of one relatively light-touch form of civic education, face-to-face canvassing, which has been effective in other contexts. In terms of Harder and Krosnick (2008), it may be that the reduction in difficulty due to localization may vastly outstrip the increases in citizen ability due to our civic information treatment, and that stronger versions of the latter may generate a detectable effect. Future work might consider variations on the civic education treatment studied here, varying the content of the educational material and the depth or frequency at which it is delivered. Second, our blocking strategy focuses on poverty, one important element of economic context. Recent work demonstrates that also another important element, economic inequality, may function to condition political preferences (Sands 2017). Future work might examine whether the effects of inequality on political preferences extend to formal political participation. Finally, voter registration in fledgling democracies may be conditioned by ethnic or religious contexts, local institutions, and networks. Future work could explore more complex designs aimed at differentiating effects due to social-contextual factors from those due to geography.

Finally, to what extent do the results from this study generalize beyond our study site? There are good grounds to expect external validity with respect to other polling stations in the seven counties since our polling stations were drawn randomly from larger populations. In Appendix K, we compare the national distribution of poverty and population density with that of our sampled polling stations. ${ }^{40}$ Although the sample excludes the extreme polling stations, it overlaps with the vast majority of the national distributions. Furthermore, our results suggest that scaling-up the policy to even poorer and more sparsely populated areas may lead to even higher registration gains. Would our results replicate beyond Kenya ${ }^{41}$ We have little direct empirical leverage over this

\footnotetext{
${ }^{40}$ We do not have data on the locations of the constituency offices in constituencies not included in our study. Thus, we do not present sample-to-population comparisons to our third blocking variable, distance to the constituency election office.

${ }^{41}$ Evrensel (2010) mentions similar voter registration problems related to cost/distance-based disenfranchisement in Ghana (pp. 2, 14), DRC (pp. 58, 81, 91, 95), Mozambique (pp. 224, 228), and South Africa (in
} 
question. It is worth noting, however, that the environment of our study is similar to that found in many developing countries on some key dimensions. In most developing countries, policy decisions related to election administration are centralized; state capacity and bureaucratic outreach remain weak; and citizens are poor, living far away from registration opportunities or in sparsely populated areas. For example, among the 46 countries classified by the World Bank as Sub Saharan Africa, Kenya ranks as only the 30th least densely populated country. ${ }^{42}$ In other words, the factors central to this study are clearly a more general phenomenon in the developing world.

\section{References}

Adida, Claire, Jessica Gottlieb, Eric Kramon, and Gwyneth Mcclendon. 2019. “Response Bias in Survey Measures of Voter Behavior: Implications for Measurement and Inference." Journal of Experimental Political Science forthcoming: 1-7.

Bennion, Elizabeth A., and David W. Nickerson. 2011. “The Cost of Convenience: An Experiment Showing E-Mail Outreach Decreases Voter Registration." Political Research Quarterly 64 (4): 858-69.

Bhatti, Yosef. 2012. "Distance and Voting: Evidence from Danish Municipalities." Scandinavian Political Studies 35 (2): 141-58.

Boone, Catherine. 2011. "Politically Allocated Land Rights and the Geography of Electoral Violence: The Case of Kenya in the 1990s." Comparative Political Studies 44 (10): $1311-42$.

Braconnier, Celine, Jean-Yves Dormagen, and Vincent Pons. 2017. “Voter Registration

2004, p. 345), suggesting that the broader problems explored here are not uncommon.

${ }^{42}$ These are 2017 population density estimates. Source: https:/ / data.worldbank.org/. 
Costs and Disenfranchisement: Experimental Evidence from France." American Political Science Review 111 (3): 584-604.

Brady, Henry E., and John E. McNulty. 2011. “Turning Out to Vote: The Costs of Finding and Getting to the Polling Place." American Political Science Review 105 (1): 115-34.

Bratton, Michael, Philip Alderfer, Georgia Bowser, and Joseph Temba. 1999. "The Effects of Civic Education on Political Culture: Evidence from Zambia." World Development 27 (5): 807-24.

Bratton, Michael, and Gina Lambright. 2001. “Uganda's Referendum 2000: The Silent Boycott." African Affairs 100: 429-52.

Burden, Barry C., David T. Canon, Kenneth R. Mayer, and Donald P. Moynihan. 2014. “Election Laws, Mobilization, and Turnout: The Unanticipated Consequences of Election Reform." American Journal of Political Science 58 (1): 95-109.

Burnell, Peter. 2002. “Zambia's 2001 Elections: The Tyranny of Small Decisions, 'Non-Decisions' and 'Not Decisions'." Third World Quarterly 23 (6): 1103-20.

Carter Center. 2013. “Observing Kenya's March 2013 National Elections Final Report.” Atlanta: Carter Center.

—. 2019. "Report on Legal Issues from Kenya 2017 Presidential Election." Atlanta, Georgia: Carter Center.

Cheeseman, Nic, Gabrielle Lynch, and Justin Willis. 2014. “Democracy and Its Discontents: Understanding Kenya's 2013 Elections." Journal of Eastern African Studies 8 (1): $2-24$.

Collier, Paul, and Pedro C. Vicente. 2012. “Violence, Bribery, and Fraud: The Political 
Economy of Elections in Sub-Saharan Africa." Public Choice 153 (1-2): 117-47.

Dale, Allison, and Aaron Strauss. 2009. “Don't Forget to Vote: Text Message Reminders as a Mobilization Tool." American Journal of Political Science 53 (4): 787-804.

De Kadt, Daniel. 2017. "Bringing the Polls to the People: How Electoral Access Encourages Turnout But Exacerbates Political Inequality." Working Paper.

Duflo, Esther, Rachel Glennerster, and Michael Kremer. 2008. “Using Randomization in Development Economics Research: A Toolkit." In Handbook of Development Economics, edited by T. Paul Schultz, 3895-3962. Amsterdam: Elsevier.

Dyck, Joshua J., and James G. Gimpel. 2005. “Distance, Turnout, and the Convenience of Voting." Social Science Quarterly 86 (3): 531-48.

Elklit, Jørgen. 1999. “Electoral Institutional Change and Democratization: You Can Lead a Horse to Water, But You Can't Make it Drink." Democratization 6 (4): 28-51.

ELOG. 2017. “One Country, Two Elections, Many Voices!: The Kenya 2017 General Elections and The Historic Fresh Presidential Election." Nairobi: Elections Observation Group.

Evrensel, Astrid. 2010. Voter Registration in Africa. Johannesburg: EISA.

Ferree, Karen E, Danielle F Jung, Robert A Dowd, and Clark C Gibson. 2018. “Election Ink and Turnout in a Partial Democracy." British Journal of Political Science forthcoming: $1-17$.

FIDA. 2013. “Key Gains and Challenges: A Gender Audit of Kenya's 2013 Election Process." Nairobi: Federation of Women Lawyers Kenya.

Finkel, Steven E, Jeremy Horowitz, and Reynaldo T Rojo-Mendoza. 2012. “Civic Education and Democratic Backsliding in the Wake of Kenya's Post-2007 Election Violence." 
The Journal of Politics 74 (1): 52-65.

Green, Donald P, and Alan S Gerber. 2015. “What Works, What Doesn't, and What's Next." In Get Out the Vote. Washington, D.C.: Brookings Institution Press.

Harder, Joshua, and Jon A Krosnick. 2008. “Why Do People Vote? A Psychological Analysis of the Causes of Voter Turnout." Journal of Social Issues 64 (3): 525-49.

Herron, Michael C, and Daniel A Smith. 2013. "The Effects of House Bill 1355 on Voter Registration in Florida." State Politics E Policy Quarterly 13 (3): 279-305.

Ichino, Nahomi, and Matthias Schundeln. 2012. “Deterring or Displacing Electoral Irregularities? Spillover Effects of Observers in a Randomized Field Experiment in Ghana." The Journal of Politics 74 (01): 292-307.

IEBC. 2017. "Media Release: Report on Audit of the Register of Voters." Nairobi.

IED. 2002. "Registration of Voters in 2002: An Audit Report." Nairobi: Institute for Education In Democracy.

— 2007. "Pre-Elections Observation: Registration of Voters in 2007 an Audit." Nairobi: Institute for Education In Democracy.

IFES. 2005. Getting to the CORE: A global survey on the cost of registration and elections. Washington, D.C.

IREC. 2008. Report of the Independent Review Commission on the General Elections Held in Kenya on 27 December 2007. Nairobi: Government Printer.

Isaksson, Ann-Sofie. 2014. "Political Participation in Africa: The Role of Individual Resources." Electoral Studies 34: 244-60.

Kanyinga, Karuti. 2009. "The Legacy of the White Highlands: Land Rights, Ethnicity and the Post-2007 Election Violence in Kenya." Journal of Contemporary African Studies 27 
(3): $325-44$.

Karlan, Dean, Margaret McConnell, Sendhil Mullainathan, and Jonathan Zinman. 2016. "Getting To the Top of Mind: How Reminders Increase Saving." Management Science 62 (12): 3393-3411.

Kolstad, Ivar, and Arne Wiig. 2016. “Education and Electoral Participation: Reported Versus Actual Voting Behaviour." Applied Economics Letters 23 (13): 908-11.

Kramon, Eric. 2016. “Electoral Handouts as Information: Explaining Unmonitored Vote Buying." World Politics 68 (3): 454-98.

Lewis, John, and Archie E Allen. 1972. "Black Voter Registration Efforts in the South." Notre Dame Law Review 48: 105-32.

Malhotra, Neil, Melissa R Michelson, Todd Rogers, and Ali Adam Valenzuela. 2011. “Text Messages as Mobilization Tools: The Conditional Effect of Habitual Voting and Election Salience." American Politics Research 39 (4): 664-81.

Marx, Benjamin, Vincent Pons, and Tavneet Suri. 2017. “The Perils of Voter Mobilization." Vol. 23946. NBER Working Paper Series.

McCauley, John F. 2014. "The Political Mobilization of Ethnic and Religious Identities in Africa." American Political Science Review 108 (4): 801-16.

McNulty, John E., Conor M. Dowling, and Margaret H. Ariotti. 2009. “Driving Saints to Sin: How Increasing the Difficulty of Voting Dissuades Even the Most Motivated Voters." Political Analysis 17 (1): 435-55.

Moore, Ryan T. 2012. “Multivariate Continuous Blocking to Improve Political Science Experiments." Political Analysis 29: 460-79.

Mueller, Susanne D. 2008. “The Political Economy of Kenya's Crisis.” Journal of Eastern 
African Studies 2 (2): 1753-1055.

Mvukiyehe, Eric, and Cyrus Samii. 2017. “Promoting Democracy in Fragile States: Field Experimental Evidence from Liberia." World Development 95: 254-67.

Neggers, Yusuf. 2018. “Enfranchising Your Own? Experimental Evidence on Polling Officer Identity and Electoral Outcomes in India." American Economic Review 108 (6): $1288-1321$.

Nickerson, David W. 2015. “Do Voter Registration Drives Increase Participation? For Whom and When?" Journal of Politics 77 (1): 88-101.

Pallister, Kevin. 2017. Election Administration and the Politics of Voter Access. London: Routledge.

Pop-Eleches, Cristian, Harsha Thirumurthy, James P Habyarimana, Joshua G Zivin, Markus P Goldstein, Damien de Walque, Leslie MacKeen, et al. 2011. “Mobile Phone Technologies Improve Adherence To Antiretroviral Treatment In a Resource-limited Setting: A Randomized Controlled Trial of Text Message Reminders." AIDS 25 (6): 825-34.

Sands, Melissa. 2017. "Exposure to Inequality Affects Support for Redistribution." Proceedings of the National Academy of Sciences 114 (4): 663-68.

Stein, Robert M., and Greg Vonnahme. 2008. “Engaging the Unengaged Voter: Vote Centers and Voter Turnout." The Journal of Politics 70 (2): 487-97.

Tomz, Michael, and Robert P Van Houweling. 2003. “How Does Voting Equipment Affect the Racial Gap in Voided Ballots?" American Journal of Political Science 47 (1): 46-60.

Verba, Sidney, Kay Scholzman, and Henry Brady. 1995. Voice and Equality: Civic Voluntarism and American Politics. Cambridge: Harvard University Press. 
Appendix for:

\title{
Electoral Administration in Fledgling Democracies:
}

\section{Experimental Evidence from Kenya}

\author{
J. Andrew Harris \\ Catherine Kamindo \\ Peter van der Windt ${ }^{1}$
}

January 12, 2020

\footnotetext{
${ }^{1}$ Corresponding author: andy.harris@nyu.edu
} 


\section{A Voter Registration Procedures Across Africa}

Table A1 presents attributes of election administration and voter registration processes in the United States, Kenya and other Africa countries. Broadly construed, the table makes two main points. First, election administration in the USA - where most current studies on voter registration take place - is much more decentralized than the Kenyan and most African contexts. Second, the Kenyan context mirrors the median African context in terms of voter registration and administration across a number of dimensions. Below, we discuss each column in turn.

- Registering authority This column tracks the body in charge of registering voters. $E M B$ refers to a national electoral management body, distinct from existing government structures. Local/Central Government refers to situations where a government body - local or national - registers voters. State/County refers to the decentralized registration in the United States where a state body or county office handles voter registration.

- Registration required to vote Is a citizen required to register in order to vote? This tracks whether a citizen must be listed on a distinct voter register in order to participate. In some contexts, national citizenship records may be used in place of a voter register.

- Method for creation of electoral register Continuous refers to a process where the voter register is open for changes and transfers throughout the electoral cycle, and closes at some point prior to an upcoming election. Periodic refers to a registration process where a voter register is compiled for each election, and discarded afterwards.

- Voting registration technology This column categorizes the methods use to compile a register. Digital/Computer means that the registering body uses specific computer 
hardware/software for voter registration. Paper/Scanning refers to a process that starts with paper forms, which are then digitized to compile a digital register. None means that the voter registration process remains manual. Mobile System means that voter registration can occur via an online system and/or SMS technology.

- Biometric data captured Biometric data include fingerprints, eye scans or other types of personal unique identifiers captured by the registering authority.

- Voting age This column reports the minimum age a citizen must be in order to vote.

- Compulsory voting This column reports whether or not voting is required of all eligible citizens.

- EMB conducts civic education This column reports whether or not the electoral management body (or other body responsible for conduct of elections) conducts civic education related to elections. 
Table A1: Comparative Data on Voter Registration, Civic Education, Registration Requirements, and EMB Structure

\begin{tabular}{|c|c|c|c|c|c|c|c|c|}
\hline Country & $\begin{array}{l}\text { Registering } \\
\text { authority }\end{array}$ & $\begin{array}{l}\text { Registration } \\
\text { required } \\
\text { to vote }\end{array}$ & $\begin{array}{l}\text { Method for } \\
\text { creation of } \\
\text { electoral register }\end{array}$ & $\begin{array}{l}\text { Voting registration } \\
\text { technology }\end{array}$ & $\begin{array}{l}\text { Biometric } \\
\text { data } \\
\text { captured }\end{array}$ & $\begin{array}{l}\text { Voting } \\
\text { age }\end{array}$ & $\begin{array}{l}\text { Compulsory } \\
\text { voting }\end{array}$ & $\begin{array}{l}\text { EMB conducts } \\
\text { civic } \\
\text { education }\end{array}$ \\
\hline$\overline{\overline{\text { USA }}}$ & "State/County & Varies & Continuous & Varies & Varies & 18 & No & Varies \\
\hline Kenya & EMB & Yes & Continuous & Digital/Computer & Yes & 18 & No & Yes \\
\hline Median African County & EMB & Yes & Continuous & Digital/Computer & Yes & 18 & No & Yes \\
\hline Algeria & Local Gov. & Yes & Continuous & Digital/Computer & Yes & 18 & No & No \\
\hline Angola & EMB & Varies & Continuous & Digital/Computer & Yes & 18 & Yes & Yes \\
\hline Benin & EMB & Yes & Continuous & Digital/Computer & Yes & 18 & No & No \\
\hline Botswana & EMB & Yes & Continuous & Paper/Scanning & No & 18 & No & No \\
\hline Burkina Faso & EMB & Yes & Continuous & Paper/Scanning & Yes & 18 & No & Yes \\
\hline Burundi & EMB & Yes & Periodic & None & No & 18 & No & Yes \\
\hline Cameroon & EMB & Yes & Continuous & Digital/Computer & Yes & 20 & No & - \\
\hline Cape Verde & EMB & Yes & Continuous & Digital/Computer & Yes & 18 & No & - \\
\hline CAR & EMB & Yes & Continuous & None & No & 18 & No & Yes \\
\hline Chad & EMB & Yes & Continuous & Digital/Computer & Yes & 18 & No & No \\
\hline Comoros & Local Gov. & Yes & Continuous & Digital/Computer & Yes & 18 & No & No \\
\hline DRC & EMB & Yes & Continuous & Digital/Computer & Yes & 18 & No & Yes \\
\hline Cote d'Ivoire & EMB & Yes & Continuous & Digital/Computer & Yes & 18 & No & Yes \\
\hline Djibouti & EMB & Yes & Continuous & None & No & 18 & No & No \\
\hline Egypt & EMB & No & NA & NA & NA & 18 & Yes & Yes \\
\hline Eq. Guinea & Central Gov. & No & NA & NA & NA & 18 & No & No \\
\hline Eritrea & EMB & Yes & Continuous & None & No & 18 & No & Yes \\
\hline Ethiopia & EMB & Yes & Periodic & None & No & 18 & No & Yes \\
\hline Gabon & Local Gov. & Yes & - & Digital/Computer & Yes & 18 & No & No \\
\hline Gambia & EMB & Yes & Periodic & Digital/Computer & Yes & 18 & No & Yes \\
\hline Ghana & EMB & Yes & Continuous & Digital/Computer & Yes & 18 & No & Yes \\
\hline Guinea & EMB & Yes & Continuous & Digital/Computer & Yes & 18 & No & Yes \\
\hline Guinea-Bissau & EMB & Yes & Periodic & Digital/Computer & Yes & 18 & No & Yes \\
\hline Lesotho & EMB & Yes & Continuous & Digital/Computer & Yes & 18 & No & Yes \\
\hline Liberia & EMB & Yes & Periodic & Paper/Scanning & Yes & 18 & No & Yes \\
\hline Libya & EMB & Yes & Continuous & Mobile System & No & 18 & No & - \\
\hline Madagascar & Central Gov. & Yes & Continuous & None & No & 18 & No & Yes \\
\hline Malawi & EMB & Yes & Continuous & Digital/Computer & Yes & 18 & No & Yes \\
\hline Mali & EMB & Varies & Continuous & NA & Yes & 18 & No & No \\
\hline Mauritania & EMB & Yes & Continuous & Digital/Computer & Yes & 18 & No & Yes \\
\hline Mauritius & EMB & Yes & Continuous & None & No & 18 & No & - \\
\hline Morocco & Central Gov. & Yes & Continuous & Digital/Computer & Yes & 18 & No & No \\
\hline Mozambique & EMB & Yes & Periodic & Digital/Computer & Yes & 18 & No & Yes \\
\hline Namibia & EMB & Yes & Continuous & Paper/Scanning & Yes & 18 & No & Yes \\
\hline Niger & EMB & Yes & Continuous & None & No & 18 & No & No \\
\hline Nigeria & EMB & Yes & Continuous & Digital/Computer & Yes & 18 & No & Yes \\
\hline Congo Brazzaville & Central Gov. & Yes & - & - & - & 18 & No & No \\
\hline Rwanda & EMB & Yes & Periodic & Digital/Computer & Yes & 18 & No & Yes \\
\hline Sao Tome and Principe & - & Yes & Continuous & Digital/Computer & Yes & 18 & No & - \\
\hline Senegal & Central Gov. & Varies & Continuous & Digital/Computer & Yes & 18 & No & No \\
\hline Seychelles & Central Gov. & Yes & Continuous & Digital/Computer & No & 18 & No & No \\
\hline Sierra Leone & EMB & Yes & Periodic & Digital/Computer & Yes & 18 & No & Yes \\
\hline Somalia & EMB & Yes & Continuous & Digital/Computer & Yes & 18 & No & - \\
\hline South Africa & EMB & Yes & Continuous & Paper/Scanning & No & 18 & No & Yes \\
\hline South Sudan & - & Yes & Continuous & None & No & - & - & - \\
\hline Sudan & EMB & Yes & Continuous & None & No & 18 & No & Yes \\
\hline Swaziland & EMB & Yes & Periodic & Paper/Scanning & Yes & 18 & No & Yes \\
\hline Tanzania & EMB & Yes & Continuous & Paper/Scanning & Yes & 18 & No & Yes \\
\hline Togo & EMB & Yes & Continuous & Digital/Computer & Yes & 18 & No & No \\
\hline Tunisia & EMB & Yes & Continuous & Mobile System & No & 18 & No & Yes \\
\hline Uganda & EMB & Yes & Continuous & Digital/Computer & Yes & 18 & No & Yes \\
\hline Zambia & EMB & Yes & Continuous & Digital/Computer & Yes & 18 & No & Yes \\
\hline Zimbabwe & EMB & Yes & Continuous & Digital/Computer & Yes & 18 & No & Yes \\
\hline
\end{tabular}

Note: Data are drawn from IDEA Electoral Management Design Database, IDEA ICTs in Elections Database, ACE Project

Comparative Database, and the authors' own research. Missing data are denoted by a dash. 


\section{B Literature Overview: Civic Education}

This section provides an overview of the empirical literature on the relationship between civic education and political participation and knowledge. Given the wide variation in civic education interventions, the intention of this appendix is to better situate our civic education intervention in the broader literature.

Table A2 gives summary information about other studies that investigate the impact of civic education on political behavior and knowledge, specifically: voter registration (Reg.), turnout (Turnout), other forms of political participation like participation in election campaigns, contact with public officials, etc. (Other) and/or political knowledge (Know.). The table indicates the mode delivery: Canvassing (C), School-based curriculum (S), townhall meetings $(\mathrm{T})$, workshops $(\mathrm{W})$, the introduction of exams $(\mathrm{E})$ and other modes like drama, media spots, concerts, and puppet shows $(\mathrm{O})$. We indicate whether the intervention targeted village populations (V), students (S), or specific leaders such as women leaders or village chiefs (L). Finally, we report the typical length of participant exposure to the civic education intervention. Subsequently, the table includes whether a study's outcome is based on administrative (A), behavioral (B) or self-reported (S) data, and whether the study is experimental (E) or observational (O) in design. The table also shows whether the study's unit of analysis is the individual (I) or the polling station (P). The table also summarizes the results of civic education across the four outcomes of interest: " + " indicates an overall positive impact; "-" a negative impact; " 0 " no evidence for impact; and "." indicates that the outcome was not explored. Finally, we list what subgroups the study explores.

The inclusion criteria were as follows. We focus on articles in the following seven journals: American Journal of Political Science, American Political Science Review, British Journal of Political Science, Comparative Political Studies, Journal of Politics, Quarterly 
Journal of Political Science, and World Development. We searched for the term "civic education" in Google Scholar and in each of the journals individually. We kept those articles that have civic education as independent variable and at least one of the earliermentioned four dependent variables. In addition, we also report such articles from other journals when they have 50 or more citations in Google Scholar (on August 7, 2019). Table A2 includes only studies that investigate the impact of civic education. That is, we include studies that focus on civics courses or civic education programs, but exclude studies that explore the impact of education more broadly (e.g. Sondheimer et al 2010). ${ }^{2}$

We highlight five observations from Table A2. First, there are only two other studies that explore the impact of civic education on voter registration (the key outcome in this study).

Second, there is much variation in "civic education". Specifically, nine out of fourteen studies explore interventions that target (often high school) students via their curriculum or the introduction of civics exams. In contrast, seven out of fourteen studies explore interventions that target other populations via townhall meetings, workshops, or other modes of delivery. The interventions under study also differ considerably in the average participant's length of exposure. While many curriculum-based interventions target students for terms at a time, other modes of delivery are often shorter like two or three half day sessions or one hour town hall meetings.

Third, the civic education intervention we explore is similar to the mode of delivery in only two other studies. Furthermore, the canvassing intervention we explore here involved one-on-one household-level discussions that lasted around ten to thirty minutes. The average participant's length of exposure is shorter than the interventions explored by

\footnotetext{
${ }^{2}$ Note also that we include studies that provide general information about the importance and/or the process of political participation, but exclude those studies that provide information about the performance of political representatives. We thus did not include the recent set of studies conducted in Dunning et al (2019), which find no evidence that such voter information campaigns shape voter behavior.
} 
other studies.

Fourth, few other studies build on administrative data and an experimental design. In fact, ten of the fourteen studies build solely on self-reported data to measure outcomes, and only three of the fourteen studies build on an experimental design.

Finally, the null result we find related to civic education and registration does not stand out from other studies. Of the two other studies that explore the impact of civic education on registration one finds a null result, and one finds a positive result. The latter, however, does not build on an experimental design and makes use of self-reported data. Moving to results related to turnout, other forms of political participation and knowledge, we observe that there is also little evidence that civic education improves turnout. In contrast, there seems to be quite consistent evidence that civic education leads to improvements in other forms of political participation and political knowledge. 
Table A2: Studies on the Relationship between Civic Education and Political Behavior and Knowledge

\begin{tabular}{|c|c|c|c|c|c|c|c|c|c|c|c|c|c|c|c|}
\hline \# & Study & Journa & itation & Country & Mode & Targ & t Length & $\mathrm{Ou}$ & $2 \mathrm{De}$ & $\mathrm{U}_{1}$ & Reg & urne & Dthe & Know & Subgroup \\
\hline$\overline{\mathrm{NA}}$ & This study & NA & NA & Kenya & $\overline{\mathrm{C}}$ & $\mathrm{V}$ & One time 10-30 minutes & $\mathrm{A}$ & $\bar{E}$ & I;P & $\overline{0}$ & $\overline{0} 0$ & . & . & Poverty; Isolation; Density \\
\hline$\overline{1}$ & Langton et al (1968) & APSR & 600 & USA & $\mathrm{S}$ & $\mathrm{S}$ & 1 school year & $\mathrm{S}$ & $\mathrm{O}$ & I & . & & . & 0 & Race \\
\hline 2 & Pasek et al (2018) & ADS & 219 & USA & $\mathrm{S}$ & $\mathrm{S}$ & 1 or 2 semesters & $\mathrm{S}$ & $\mathrm{O}$ & I & . & 0 & . & + & None \\
\hline 3 & Finkel (2002) & JOP & 173 & Dom. Rep.; SA & $\mathrm{C} ; \mathrm{S} ; \mathrm{O}$ & $\mathrm{V} ; \mathrm{L}$ & Multiple & $\mathrm{S}$ & $\mathrm{O}$ & I & . & . & + & + & Exposure; Pol. resources \\
\hline 4 & Finkel et al (2005) & PP & 162 & South Africa & $\mathrm{S}$ & $\mathrm{S}$ & $>1$ per week for 2 years & $\mathrm{S}$ & $\mathrm{O}$ & I & . & . & . & + & None \\
\hline 5 & Finkel et al (2000) & WD & 127 & Dom. Rep. & $\mathrm{C} ; \mathrm{S} ; \mathrm{O}$ & $\mathrm{V} ; \mathrm{L}$ & Multiple & $\mathrm{S}$ & $\mathrm{O}$ & I & 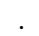 & . & . & + & None \\
\hline 6 & Finkel et al (2011) & AJPS & 118 & Kenya & W;T;O & $\mathrm{V}$ & Multiple & $\mathrm{S}$ & $\mathrm{O}$ & I & . & . & + & + & Exposure; Pol. resources \\
\hline 7 & Bratton et al (1999) & WD & 107 & Zambia & $\mathrm{C} ; \mathrm{S} ; \mathrm{O}$ & $\mathrm{V} ; \mathrm{S}$ & Multiple & $\mathrm{S}$ & $\mathrm{O}$ & I & + & . & + & + & None \\
\hline 8 & Gottlieb (2016) & AJPS & 93 & Mali & W & $\mathrm{V}$ & 2 or 3 halfday sessions & $\mathrm{S} ; \mathrm{B}$ & $\mathrm{E}$ & I & & . & + & + & None \\
\hline 9 & Slomcyznski et al (1998) & PP & 75 & Poland & $\mathrm{s}$ & $\mathrm{S}$ & 30 hours & $\mathrm{s}$ & $\mathrm{O}$ & I & & . & . & + & None \\
\hline 10 & Finkel et al (2012) & JOP & 58 & Kenya & $\mathrm{W} ; \mathrm{O}$ & $\mathrm{V}$ & Multiple & $\mathrm{S}$ & $\mathrm{O}$ & I & . & . & + & + & Exposure to violence \\
\hline 11 & Green et al (2011) & JOP & 55 & USA & $\mathrm{S}$ & $\mathrm{S}$ & 21 classroom lessons & $\mathrm{S}$ & $\mathrm{E}$ & I & . & . & . & + & None \\
\hline 12 & Persson et al (2010) & SPS & 53 & Sweden & $\mathrm{S}$ & $\mathrm{S}$ & 100 hours & $\mathrm{S} ; \mathrm{B}$ & $\mathrm{O}$ & I & . & 0 & 0 & 0 & None \\
\hline 13 & Campbell et al (2016) & APSR & 22 & USA & $\mathrm{E}$ & $S$ & NA & $\mathrm{B}$ & $\mathrm{O}$ & I & & & . & + & Incentivized; Race \\
\hline 14 & Mvukiyehe et al (2017) & WD & 21 & Liberia & $\mathrm{T}$ & $\mathrm{V}$ & $>1$ hour & S;B;A & $\mathrm{E}$ & I;P & 0 & 0 & + & + & None \\
\hline
\end{tabular}

Note: Journal: ADS = Applied Development Science; WD = World Development; SPS = Scandinavian Political Science; APSR = American Political Science Review; JOP = Journal of

Politics; PP = Political Psychology; AJPS = American Journal of Political Science. Citation counts from Google Scholar (August 7, 2019). Mode: C = Canvassing, S = School-based curriculum, $\mathrm{T}=$ Townhall meetings, $\mathrm{W}=$ Workshops, $\mathrm{E}=$ Exams, $\mathrm{O}=$ Other. Target: $\mathrm{V}=$ Village populations, $\mathrm{S}=\mathrm{Students}, \mathrm{L}=\mathrm{Leaders}$. Outcome: $\mathrm{A}=\mathrm{Administrative} ; \mathrm{S}=$ Self-reported; $\mathrm{B}=$ Behavioral. Design: $\mathrm{E}=$ Experiment; $\mathrm{O}=$ Observational. Unit: $\mathrm{P}=$ Polling station; $\mathrm{I}=$ Individual. Reported results relate to the full sample, not subgroup analyses. 


\section{County and Polling Station Selection and Assignment to Treatment}

\section{C.1 County Selection}

The study took place in seven of Kenya's 47 counties: Bungoma, Kwale, Kisumu, Nyamira, Nyandarua, Kericho, and Makueni. The selection of these counties took place in two steps. First, we choose counties that have polling stations that are similar across three characteristics: poverty; distance from the registration office; and population density. Specifically, we use a covariance matrix to select counties that are similar on these three characteristics. Then, we select seven counties that have a cosine-distance higher than 0.9 and taking into account IEBC's political sensitivities. We measure these variables in the following way:

1. Poverty The percentage of people below the poverty line at that polling station, average across county. Information on the local poverty rates for each polling station comes from http://www.worldpop.org. The data are at a high geographic resolution. We used a Voronoi diagram to measure a polling station's level of poverty.

2. Distance to registration office Normally, citizens register at the registration office. Each constituency has one registration office. We obtained information from the IEBC about all polling station locations. From this we create a distance indicator between the polling station and the registration office based on three measures: 1) kilometer distance as the bird flies, 2) kilometer walking distance from Googlemaps, and 3) kilometer driving distance from Googlemaps.

3. Population density Measures as the population density within a 500 meter radius around a polling station. Datasource: http://www.worldpop.org. 
Table A3 presents information about poverty, distance and population density for each county.

Table A3: County Information

\begin{tabular}{rccccccc}
\hline County & Bungoma & Kericho & Kisumu & Kwale & Makueni & Nyamira & Nyandarua \\
\hline Total \# of Polling Stations & 806 & 530 & 528 & 415 & 866 & 333 & 350 \\
\# of Sampled Stations & 252 & 252 & 252 & 252 & 252 & 162 & 252 \\
Sample as \% of Total & 31 & 48 & 48 & 61 & 29 & 49 & 72 \\
\hline Poverty & 0.46 & 0.44 & 0.46 & 0.52 & 0.43 & 0.38 & 0.27 \\
Distance & 17.25 & 18.31 & 20.68 & 27.98 & 27.03 & 13.62 & 18.99 \\
Population Density & 73 & 50 & 84 & 28 & 27 & 92 & 31 \\
\hline
\end{tabular}

Note: Poverty is the percentage of the population below poverty line; distance is kilometers distance from the registration office; population Density is per $\mathrm{km}^{2}$.

Second, conditional on being sufficiently similar, we selected seven counties based upon their support for the government. Specifically, we choose two pro-government counties (Kericho, Nyandarua), three pro-opposition counties (Kisumu, Kwale, Makueni), and two split counties (Bungoma, Nyamira). For the county selection we collaborated with the IEBC in order to avoid perceptions of political bias.

\section{C.2 Polling Station Selection and Assignment to Treatment}

The sampling frame is a complete list of the 3,828 polling stations in the selected seven counties. For all counties except Nyamira, we sampled $42 \times 6=252$ polling stations to be part of our study. Given the higher population density of Nyamira County (and thus higher spatial density of polling stations), we only sampled $27 \times 6=162$, in order to maintain sufficient distance between treated polling stations to minimize spillovers. The study thus targets a total of 1,674 polling stations across seven counties in Kenya. Our strategy to sample polling stations and assign them to treatment had three main goals: 1) sample the number of polling stations as indicated above, 2) minimize the chances of spillovers, and 3) randomly assign the six treatments to polling stations within blocks that consist out of similar polling stations. We undertook the follow nine steps for each county: 
1. We randomly select 1 polling station out of all possible polling stations;

2. Drop those units within 1.5 kilometers distance of the selected polling station; ${ }^{3}$

3. Randomly select a second polling station among those that are left;

4. Drop those units within 1.5 kilometers distance of this second unit;

5. Etc. Until we are left with exactly 252 (or 162 for Nyamira) polling stations sampled.

6. From those selection polling stations we create blocks of six that are similar based on the above three characteristics (poverty, distance and population density), using the technique discussed in Moore (2012);

7. Subsequently, within each block of six polling stations we assign the six treatments.

8. Conduct steps 1 to 8 a total of $1,000,000$ times.

9. Of the 1,000,000 outputs, we choose the one with the best balance on the above set of blocking covariates.

Two final notes are in order. First, we choose not to do a simple random sample of 252 polling stations (or 162 for Nyamiria) because there is only a small probability that we get units where all selected polling stations are more than 1.5 kilometers apart from each other. Second, we conduct the steps within county, not within constituency (the electoral unit below county). The latter would have given blocks consisting of more diverse polling stations and thus less efficient estimates.

\footnotetext{
${ }^{3}$ We choose 1.5 kilometers as a threshold after consultation with the IEBC regarding the minimum distance that would create a functional buffer between local communities.
} 


\section{Statistical Power}

In this appendix, we discuss statistical power. We did not include power calculation in the pre-analysis plan as we had little ex ante information or strong priors about the magnitude of treatment effects or their standard deviations. That said, the main results in Table 2 suggest that the study is powered to detect small effects. Column 2, our pre-registered analysis, for example, identifies significant differences between the status quo and four of the five treatment conditions. The only intervention for which we are not able to identify such an effect is the SMS effect, of which the effect is extremely small.

In addition, this appendix presents the results of an ex post power calculation. Specifically, we explore how large the sample size must be to detect an effect at at least the 0.05 level, given the observed data. To do so, we simulate our experiment 5,000 times across a number of sample sizes, randomly drawing observations with replacement from the observed data. Specifically, for each simulation, we randomly sample a dataset of sample size $N$ from the actual data, and then use this sample to regress the dependent variable on the treatment vector, recording whether or not the estimated p-value for that simulation for each factorial treatment is less than or equal to 0.05 . In this way, we use the observed data to address questions related to sample size and the detection of effects for a given alpha level. We repeat simulations for $N$ ranging from 10 to 575 per treatment.

Figure A1 plots $N$ on the x-axis and power - the percentage of p-values less than or equal to 0.05 - for each factorial treatment on the y-axis. The results show that, for the magnitude of the localization-related interventions, we are well-powered and, given our blocked design, have sample size to spare. Related to the effects of canvassing and SMS

only interventions, even if we had increased our sample size by any appreciable amount, we would reach the same conclusions. 
Figure A1: Ex Post Power Calculations

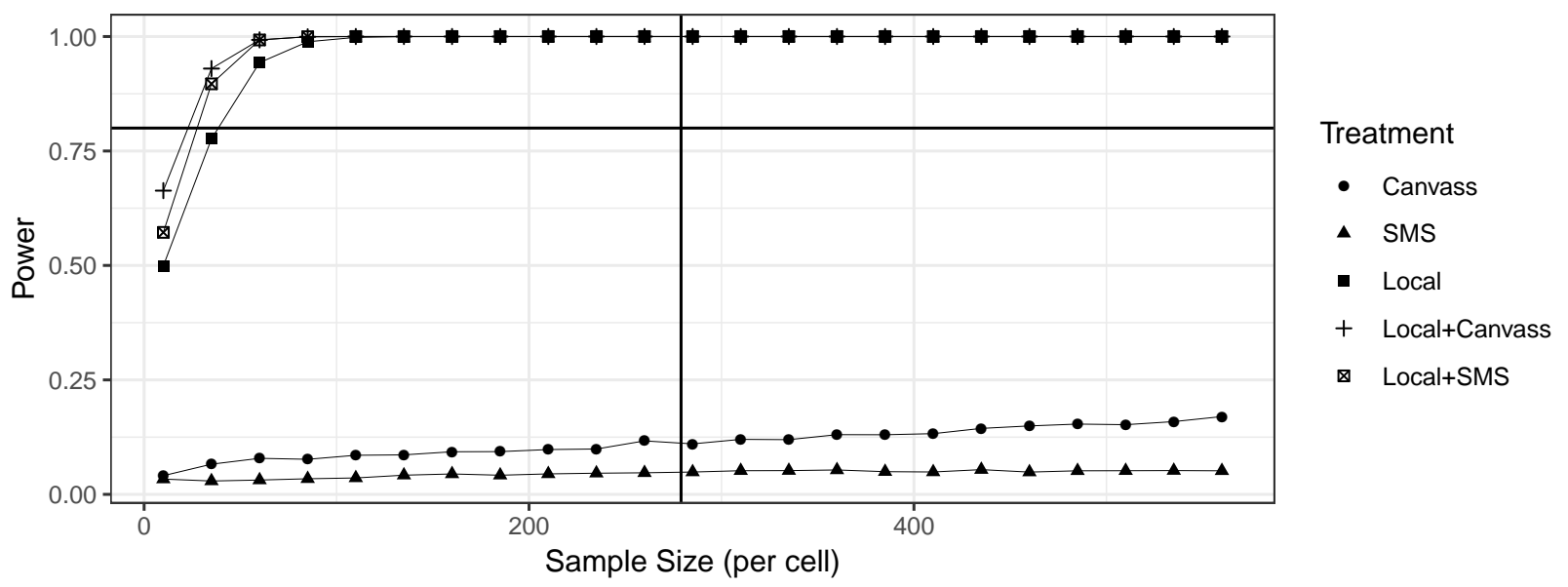

Note: Power given sample size conditional on the observed data. For each cell sample size $N$, we randomly select $N$ observations for each factorial cell, for a total sample size of $6 \mathrm{~N}$. We then regress the sampled outcome vector on the sampled treatment vector, recording the p-values for each coefficient. We do this 5,000 times for each $N$. Next, for each $N$, we calculate the power (y-axis) by calculating the proportion of p-values less than or equal to 0.05 , the chosen alpha-level. Vertical line indicates the number of units per treatment in this study (279). 


\section{E Monitoring}

This section describes the monitoring effort that was carried out alongside the project. We randomly selected ten percent of the 1,674 polling stations to be monitored. ${ }^{4}$ We hired one person per county to carry out the monitoring, given funding constraints. Because of this, not all monitoring visits could be completed, simply due to logistical constraints of getting from one randomly selected intervention site to another in a given day across an entire county. As a result, of the 167 planned monitoring visits, 133 (80\%) were carried out. Table A4 presents descriptive statistics on the monitoring effort.

Table A4: Descriptive Statistics on Project Monitoring.

\begin{tabular}{lcccc}
\hline \hline & Canvassing & Local & Local+Canvassing & Local+SMS \\
\hline Assigned Visits & 52 & 42 & 36 & 37 \\
Completion Rate & $73 \%$ & $79 \%$ & $81 \%$ & $86 \%$ \\
Observed Compliance & $61 \%$ & $91 \%$ & $79 \%$ & $88 \%$ \\
\hline \hline
\end{tabular}

Top row reports the number of monitoring visits assigned to a given treatment. Second row presents the percentage of those visits completed. Third row presents the percentage of visits where treatment compliance was directly observed by monitors.

For the interventions including localization, the monitors observed the correct intervention $86 \%((91+79+88) / 3)$ of the time. For the canvassing-only intervention, monitors directly observed compliance in 61\% (23) of the 38 monitored interventions. For 12 of the 38 monitored canvassing interventions, monitors did not directly observe the IEBC canvassers in the field. Given the mobility of canvassers, this could mean one of two things. First, it could mean that the IEBC canvassers were not doing the intervention. Second, it could mean that the IEBC canvassers were in the field, but that the monitors could not locate them. We cannot distinguish between these two possibilities, and report the directly observed compliance above. If we assume that the two scenarios are equally likely, then

\footnotetext{
${ }^{4}$ In fact, we selected from the polling stations receiving localization and/or canvassing related interventions. We did not aim to monitor the SMS intervention in the field because this was provided directly by a bulk SMS provider in Nairobi.
} 
canvassing would have been correctly implemented about $82 \%$ of the time, which is on par with the localization interventions ( $86 \%$ compliance).

For 3 of the 38 monitored canvassing interventions, our monitors observed registration occuring alongside canvassing. Our data during the intervention period corroborates this, showing that a total of 31 individuals were registered during those two non-compliant interventions, which is consistent with the effects of localization. This raises issues of compliance, and how non-compliance may affect our results. This is especially a concern in the canvassing intervention. More specifically, the small estimated effects could be the result of noncompliance, rather than true treatment effect near zero. As discussed above, there were two potential types of non-compliance - canvassers not showing up (which would attenuate the estimated effect of canvassing) and canvassers showing up with voter registration kits (which would magnify the effect of canvassing, assuming that localization has some positive effect).

As a rough check of the within-intervention averages in the monitored units, the verified canvassing treatment elicited 1.5 registered voters on average; verified localization interventions yielded 10 registered voters on average. This comparison of the responses observed in verified interventions suggests two things. First, the magnitude of the difference in response between canvassing and localization interventions is large. Second, small amounts of non-compliance in the canvassing group in the form of non-compliant localization could easily bias canvassing estimates upward, given the magnitude of this difference. Put another way, upward bias from small amounts of non-compliance via localization is likely to swamp downward bias from even moderate amounts of unimplemented canvassing. This may be one reason why we see small positive effects to canvassing in some specifications: given that $\mathrm{CEC}$ 's hope to meet registration quotas, they occassionally sent registration equipment out with canvassers. 
More broadly, our compliance rates are in line with other work in the social sciences. ${ }^{5}$ Table A5 below presents compliance rates in a set of recent social science studies from economics, public health, and political science, demonstrating compliance rates in those studies. With respect to the specific context of working within field offices of a national quasi-government organization, the rates of compliance we observe are on par with analogous rates of absenteeism in the education sector, which stood at 22\% in 2015 (Jones et al 2017). ${ }^{6}$ This comparison supports the assertion that our intent-to-treat estimates are based on credible real-world compliance (i.e., people showing up to work and doing their job) if the interventions studied here were implemented as policy.

Table A5: Compliance in a Set of Recent Social Science Experiments

\begin{tabular}{lccc} 
Citation & Journal & Intervention & Compliance Rate \\
\hline \hline Bail et al. (2018) & PNAS & Twitter Bots & $62 \%$ \\
Ichino and Schundeln (2012) & JOP & Observers & $85 \%$ \\
Pop-Eleches et al. (2011) & AIDS & SMS & $83 \%$ \\
Panagopoulos (2009) & PRQ & GOTV Calls & $58 \%-63 \%$ \\
Nickerson (2008) & APSR & Canvassing & $33 \%-46 \%$ \\
Kremer and Miguel (2004) & Econometrica & Medical Treatment & $55 \%-80 \%$ \\
\hline
\end{tabular}

Table reports information on treatment compliance as reported by authors in a set of recent experimental papers. A number of the papers above reported compliance information for multiple experiments, leading us to report a range of compliance percentages.

\footnotetext{
${ }^{5}$ Our search of recent experimental work revealed that few experiments actually discuss or report on compliance in detail.

${ }^{6}$ Chaudhury et al (2006) surveys the broader state-of-research on absenteeism in healthcare and education in the developing world, and finding average rates of absenteeism at $19 \%$ in primary schools and $35 \%$ in health centers.
} 


\section{F Balance}

The analyses in this paper rely on randomization, which guarantees that the treatment and control areas are similar in expectation. In practice, however, it is possible for them to differ simply by virtue of unlucky draws. To test this, we compare the different treatment conditions across 19 variables:

- Poverty See Section C.1.

- Population Density See Section C.1.

- Distance See Section C.1.

- Nighttime Lights Version 4 DMSP-OLS Nighttime Lights Time Series, 2013, average stable lights. Source: https://ngdc.noaa.gov/eog/dmsp/downloadV4composites. html.

- Terrain Derived from SRTM DEM using raster package in R.

- Slope Derived from SRTM DEM using raster package in $\mathrm{R}$.

- Elevation SRTM elevation data. Source: https://www2.jpl.nasa.gov/srtm/

- Health The probability of skilled birth attendance (SBA) during delivery. Source: http://www.worldpop.org.

- Dependency Ratio Sub-national dependency ratios. The ratio of dependents (both young, 0 to 14 , and old, 65+) upon the working age population. Source: http: //www.worldpop.org.

- Literacy Proportion of women aged 15-49 classed as literate in 2008. Source: http: //www.worldpop.org.

- Mean Age Age of individuals that were registered to voter in the 2013 elections. 
Source: IEBC data.

- SD Age Standard deviation of age of individuals that were registered to voter in the 2013 elections. Source: IEBC data.

- Mean Pct. Youth Share of youth (individuals younger than 35 years old) that were registered to vote in the 2013 elections. Source: IEBC data.

- Mean Pct. Female Share of women that were registered to vote in the 2013 elections. Source: IEBC data.

- Votes Cast Total number of votes cast during the 2013 elections. Source: IEBC data.

- Kenyatta VS Share of votes cast for Kenyatta during the 2013 elections. Source: IEBC data.

- Odinga VS Share of votes cast for Odinga during the 2013 elections. Source: IEBC data.

- Turnout Percent of registered voters who voted in the 2013 elections. Source: IEBC data.

Table A6 contains covariates stored as a raster extracted from a 500 meter radius of the polling station. Table A7 contains covariates relating to the 2013 elections. Columns 1 and 2 in both tables state the intervention groups being compared. In total there are 15 comparisons between all combinations of treatment groups. The remaining columns present bootstrapped Kolgorov-Smirnoff statistic p-values (Sekhon 2011), comparing the distributions of covariates across interventions groups. The p-values suggest that our samples are well-balanced, which is consistent with what is to be expected given the random assignment. 
Table A6: Kolgorov-Smirnoff Balance Tests: Spatial Covariates

\begin{tabular}{|c|c|c|c|c|c|c|c|c|c|c|c|}
\hline Group 1 & Group 2 & Poverty & Pop. Dens. & Distance & Lights & Terrain & Slope & Elev. & Health & Dep. Ratio & Literacy \\
\hline Canvass & Control & 0.99 & 1.00 & 0.99 & 0.16 & 0.67 & 0.67 & 0.86 & 0.50 & 1.00 & 0.70 \\
\hline SMS & Control & 1.00 & 0.95 & 0.98 & 0.52 & 0.73 & 0.66 & 0.99 & 0.86 & 0.99 & 0.73 \\
\hline Local & Control & 0.99 & 0.98 & 0.91 & 0.93 & 0.85 & 0.85 & 0.63 & 0.91 & 0.96 & 0.91 \\
\hline Loc.+Canv. & Control & 0.99 & 0.85 & 0.87 & 0.82 & 0.62 & 0.55 & 0.79 & 0.60 & 1.00 & 0.79 \\
\hline Loc.+SMS & Control & 0.97 & 0.99 & 0.94 & 0.74 & 0.95 & 0.94 & 0.98 & 0.67 & 0.70 & 0.80 \\
\hline SMS & Canvass & 0.98 & 0.93 & 0.98 & 0.54 & 0.95 & 0.98 & 0.95 & 0.65 & 0.99 & 0.19 \\
\hline Local & Canvass & 0.99 & 0.96 & 0.94 & 0.44 & 0.81 & 0.68 & 0.72 & 0.35 & 0.93 & 0.57 \\
\hline Loc.+Canv. & Canvass & 0.92 & 0.74 & 0.99 & 0.45 & 0.92 & 0.87 & 0.97 & 0.75 & 1.00 & 0.23 \\
\hline Loc.+SMS & Canvass & 0.95 & 0.98 & 0.98 & 0.17 & 0.44 & 0.39 & 0.91 & 0.33 & 0.97 & 0.39 \\
\hline Local & SMS & 0.99 & 0.94 & 0.95 & 0.55 & 0.57 & 0.44 & 0.94 & 0.60 & 0.98 & 0.87 \\
\hline Loc.+Canv. & SMS & 0.89 & 0.97 & 0.97 & 0.85 & 0.91 & 0.85 & 0.85 & 0.15 & 0.98 & 0.95 \\
\hline Loc.+SMS & SMS & 0.96 & 0.88 & 1.00 & 0.20 & 0.74 & 0.67 & 0.98 & 0.96 & 0.76 & 0.65 \\
\hline Loc.+Canv. & Local & 0.95 & 0.86 & 0.91 & 0.95 & 0.91 & 0.86 & 0.86 & 0.59 & 0.99 & 0.91 \\
\hline Loc.+SMS & Local & 0.93 & 0.66 & 0.93 & 0.81 & 0.82 & 0.88 & 0.97 & 0.44 & 0.53 & 0.78 \\
\hline Loc.+SMS & Loc.+Canv. & 0.87 & 0.86 & 0.96 & 0.45 & 0.93 & 0.92 & 0.86 & 0.07 & 0.91 & 0.98 \\
\hline
\end{tabular}


Table A7: Kolgorov-Smirnoff Balance Tests: 2013 Election-Related Covariates

\begin{tabular}{|c|c|c|c|c|c|c|c|c|c|c|}
\hline Group 1 & Group 2 & Mean age & SD age & Pct. Youth & Pct. Female & Votes Cast & Kenyatta VS & Odinga VS & Turnout & Reg. Voters \\
\hline Canvass & Control & 0.97 & 0.85 & 0.61 & 0.57 & 0.28 & 0.78 & 0.94 & 0.69 & 0.17 \\
\hline SMS & Control & 0.83 & 0.43 & 0.70 & 0.88 & 0.97 & 0.83 & 0.87 & 0.24 & 0.79 \\
\hline Local & Control & 0.99 & 0.97 & 0.60 & 0.95 & 0.71 & 0.92 & 0.98 & 0.65 & 0.78 \\
\hline Loc.+Canv. & Control & 0.93 & 0.39 & 0.84 & 0.08 & 0.12 & 0.89 & 0.84 & 0.53 & 0.10 \\
\hline Loc.+SMS & Control & 0.79 & 0.96 & 0.95 & 0.09 & 0.69 & 0.98 & 0.95 & 0.70 & 0.81 \\
\hline SMS & Canvass & 0.89 & 0.41 & 0.63 & 0.87 & 0.45 & 0.75 & 0.66 & 0.79 & 0.36 \\
\hline Local & Canvass & 0.84 & 0.94 & 0.96 & 0.58 & 0.34 & 0.97 & 0.97 & 0.97 & 0.65 \\
\hline Loc.+Canv. & Canvass & 0.80 & 0.12 & 0.86 & 0.21 & 0.69 & 0.90 & 0.76 & 0.80 & 0.48 \\
\hline Loc.+SMS & Canvass & 0.78 & 0.86 & 0.82 & 0.65 & 0.39 & 0.75 & 0.99 & 0.83 & 0.28 \\
\hline Local & SMS & 0.86 & 0.73 & 0.59 & 0.91 & 0.76 & 0.88 & 0.82 & 0.93 & 0.33 \\
\hline Loc.+Canv. & SMS & 0.77 & 0.73 & 0.77 & 0.11 & 0.11 & 0.45 & 0.76 & 0.50 & 0.01 \\
\hline Loc.+SMS & SMS & 0.98 & 0.62 & 0.84 & 0.27 & 0.38 & 0.97 & 0.75 & 0.73 & 0.40 \\
\hline Loc.+Canv. & Local & 0.99 & 0.34 & 0.84 & 0.28 & 0.25 & 0.96 & 0.89 & 0.91 & 0.59 \\
\hline Loc.+SMS & Local & 0.84 & 0.86 & 0.81 & 0.27 & 0.44 & 0.97 & 0.98 & 0.68 & 0.28 \\
\hline Loc.+SMS & Loc.+Canv. & 0.96 & 0.31 & 0.97 & 0.33 & 0.26 & 0.60 & 0.74 & 0.49 & 0.35 \\
\hline
\end{tabular}

Note: Columns 1 and 2 state the intervention groups being compared. Remaining columns present bootstrapped KS statistic p-values, comparing the distributions of covariates across treatment arms. 


\section{G Treatment Effects Over Time}

While localization is likely to be effective only on the two days of the intervention when registration is present, information from canvassers or via SMS may motivate action in the days after treatment. To capture this, the (pre-registered) treatment variable defines the localization treatment as only the two days when the registration kit was at a randomly selected polling station. In contrast, the canvassing and SMS-only treatments are coded as the two intervention days plus a ten day "tail." The remaining polling station-days constitute the control condition. The ten-day tail and the asymmetry across interventions, although pre-registered and based on discussions with the IEBC, is admittedly ad hoc. As a result, in this appendix, we present results across a range of treatment specifications.

Figure A2 re-estimates the model used in Table 2's columns 4 for different treatment windows, respectively: 2 days of the intervention, 2 days of the intervention plus a ten-day tail, 2 days of the intervention plus a twenty-day tail, etc. ${ }^{7}$ Note that the dependent variable is the average registrations per polling station per day. In other words, the total number of registered individuals averaged over 2 days if there is no tail, averaged over 12 days if there is a 10 day tail, etc.

We find that the effect of the interventions involving canvassing or SMS remains similar as those report in Table 2. We also find that the localization effect is driven solely by the two-day period when the registration kit was present at the polling station. That is, the effect is strong in the two days when the intervention takes place and then averages out over time, with the effect approaching zero as more non-intervention days are added to the tail.

\footnotetext{
${ }^{7}$ June 9, 2017 (207 days after the start of the intervention) was the last day that Kenyans could register to vote. The figure therefore continues to two days plus a tail of 210 days.
} 
Figure A2: Treatment Effects for Different Time Windows

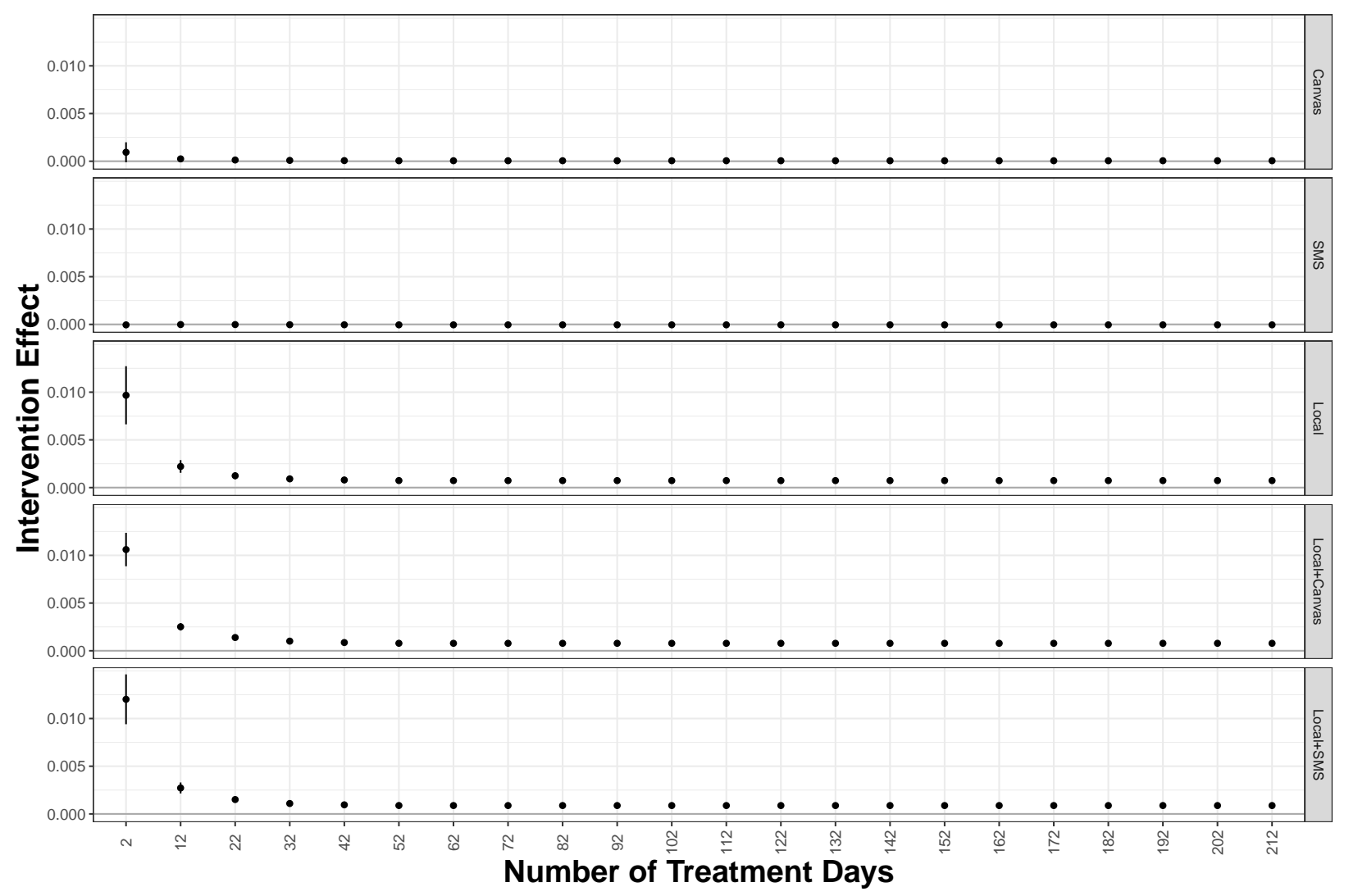

Note: Dependent variable is the average registrations per polling station per day. The $\mathrm{X}$-axis indicate the two intervention days plus the length of the "tail". Bars indicate 95\% confidence interval. 


\section{H Baseline Summary Information}

Table A8 presents descriptive statistics for the three outcome variables and the number of registered voters at a polling station, based on the month before the onset of the intervention. The table also presents descriptive statistics for the number of registered voters at a polling station in 2013 and the three blocking variables.

Table A8: Baseline Information

\begin{tabular}{rrrrrr}
\hline & Mean & SD & Min & Max & Obs. \\
\hline \# Registrations per PS day & 0.0293 & 0.4585 & 0.0000 & 33.0000 & 35112 \\
\# Registrations per PS day / 2013 reg. voters & 0.0001 & 0.0009 & 0.0000 & 0.0833 & 35112 \\
\# Registrations per PS / 2013 reg. voters & 0.0011 & 0.0044 & 0.0000 & 0.0833 & 1668 \\
\# Registrations per PS & 0.6160 & 2.3608 & 0.0000 & 33.0000 & 1672 \\
\# Registered voters in 2013 & 540.5264 & 429.0525 & 2.0000 & 6764.0000 & 1668 \\
Poverty & 0.4267 & 0.1095 & 0.1810 & 0.8989 & 1668 \\
Distance & 20.9136 & 16.2380 & 0.0390 & 179.0235 & 1668 \\
Density (x10,000) & 5.2724 & 9.0415 & 0.0000 & 231.9146 & 1668 \\
\hline
\end{tabular}

Note: PS = polling station. Polling station day information is based on the month preceding the start of the intervention (November 14, 2016). Poverty, Distance and Density are defined as before.

As expected, the average daily number of registrations per polling station in the month before the onset of the intervention (0.0293) is quite similar as those in the control group during the intervention (row "Control mean" of columns 1 to 3 in Table 2: 0.0437). 


\section{Comparison Intervention Effects}

Table 2 presents the size of the intervention effects. Do these effects differ from each other? To answer this question, Table A9 presents p-values from Wald tests, comparing the effects of the different interventions. The tests build on the model specification that we pre-registered (column 2 in Table 2). We find that across all intervention effect comparisons, with the exception of localization versus localization plus canvassing, are significantly different from each other.

Table A9: Comparison Intervention Effects

\begin{tabular}{llc} 
Intervention 1 & Intervention 2 & P-value \\
\hline \hline SMS & Canvassing & 0.00 \\
Localization & Canvassing & 0.00 \\
Localization & SMS & 0.00 \\
Localization+Canvassing & Canvassing & 0.00 \\
Localization+Canvassing & SMS & 0.00 \\
Localization+Canvassing & Localization & 0.25 \\
Localization+SMS & Canvassing & 0.00 \\
Localization+SMS & SMS & 0.00 \\
Localization+SMS & Localization & 0.00 \\
Localization+SMS & Localization+Canvassing & 0.02 \\
\hline \hline
\end{tabular}




\section{J Literature Overview: Registration and Turnout}

In this section, we summarize existing literature on improving voter registration and Get Out To Vote (GOTV), and discuss the findings of those literatures in relation to our results. Appendix Table A10 summarizes features of twenty papers from these two distinct but related literatures. First, the table presents information on twelve (descriptive or experimental) studies examining the determinants of voter registration. Inclusion criteria were articles published in political science journals that have voter registration as an outcome. Second, to situate the magnitude of our results in the much larger experimental GOTV literature, the table summarizes an additional eight GOTV papers. Inclusion criteria were publication since 2000, at least 100 citations on Google Scholar, and publication in the AJPS, APSR or the JOP. ${ }^{8}$

The interventions or independent variables in the registration literature fall into three categories: civic educational interventions, traditional GOTV interventions, and a residual category. The civic educational interventions in Mvukiyehe et al (2017), Bennion et al (2016), and Bratton et al (1999) vary widely. Mvukiyehe et al (2017) administered a civic education program in Liberia, consisting of a presentation by educators and a town-hall style discussion. The intervention in Bennion et al (2016) consisted of presentations to students by professors or peers. Bratton et al (1999) evaluates a trio of diverse civic education programs in Zambia, ranging from a formal course to community events. The GOTV interventions encompass face-to-face canvassing (Nickerson 2015, Braconnier et al 2017) and mail/email (Bennion et al 2011, Nickerson et al 2007, Gosnell 1926, Mann et al 2019). The residual category examines the effect of election observers (Ichino et al 2012, law changes (Mitchell et al 1995), and a lottery (John et al 2015).

\footnotetext{
${ }^{8}$ We considered less restrictive inclusion criteria (e.g., no time restriction, inclusion of observational studies, or fewer citations), but the list quickly ballooned to over 50 GOTV studies.
} 
Broadly construed, the effects of experimental interventions on registration mirror findings in the GOTV literature. Less expensive efforts like mail or email tend to generate little effect (a maximum of 2.2\% in Mann et al (2019)). ${ }^{9}$ Civic educational interventions have potentially larger effects (3.5\% on average), while the canvassing studies report the largest effects, averaging almost $9 \%$. Note that this broad pattern is based on relatively few studies testing a wide array of interventions in diverse contexts. Future work is needed to verify the broad pattern. That said, the pattern mirrors the findings of our work: intensive localization brings the largest gains, with less expensive canvassing and SMS providing limited or no benefit.

The magnitude of effects we find are in line with the experimental effects found in the small registration literature. Our study is perhaps most similar in spirit to Nickerson (2015), who finds that registrations increase, on average, by about $4.4 \%$ in response to a door-to-door registration drive. The magnitude we report is approximately half of this, although the effect size varies by context. The poorest subgroup in Nickerson (2015) reported a $\frac{16.4}{225}=0.073(7.3 \%)$ increase in registration, relatively to an effect of about $4.4 \%$ in the poorest block in our intervention. Interestingly, Nickerson (2015) (p. 95) notes that the average effect of $4.4 \%$ arises, "in the contemporary setting where voter registration is moderately easy." This raises the question as to whether the relatively modest results we observe (relative to Nickerson (2015)) might be driven by the more onerous nature of Kenya's voter registration processes.

Registration effects, according to the table, seem to be small relative to turnout effects reported in the GOTV literature. This may be for several reasons. First, GOTV interventions are implemented on a different population of citizens than registration studies: registered voters versus the broader eligible population. Registered voters may be more responsive

\footnotetext{
${ }^{9}$ We exclude the effects of the mail intervention in Gosnell (1926) from discussion, given that it provides little of the standard statistical reporting like standard errors present in modern studies.
} 
to interventions, given that they have already cleared the registration hurdle. Second, registration may constitute a more substantial barrier to participation for the eligible-butunregistered population relative to voting with respect to registered voters. As such, we urge caution in directly comparing magnitudes of effects in the GOTV literature with the registration literature. 


\section{Table A10: Studies on Voter Registration and Turnout Outcomes}

\# Paper

Journal Year Citations Country Treatment Reg? TO? RegATE TOATE Type RCT? Unit

Design

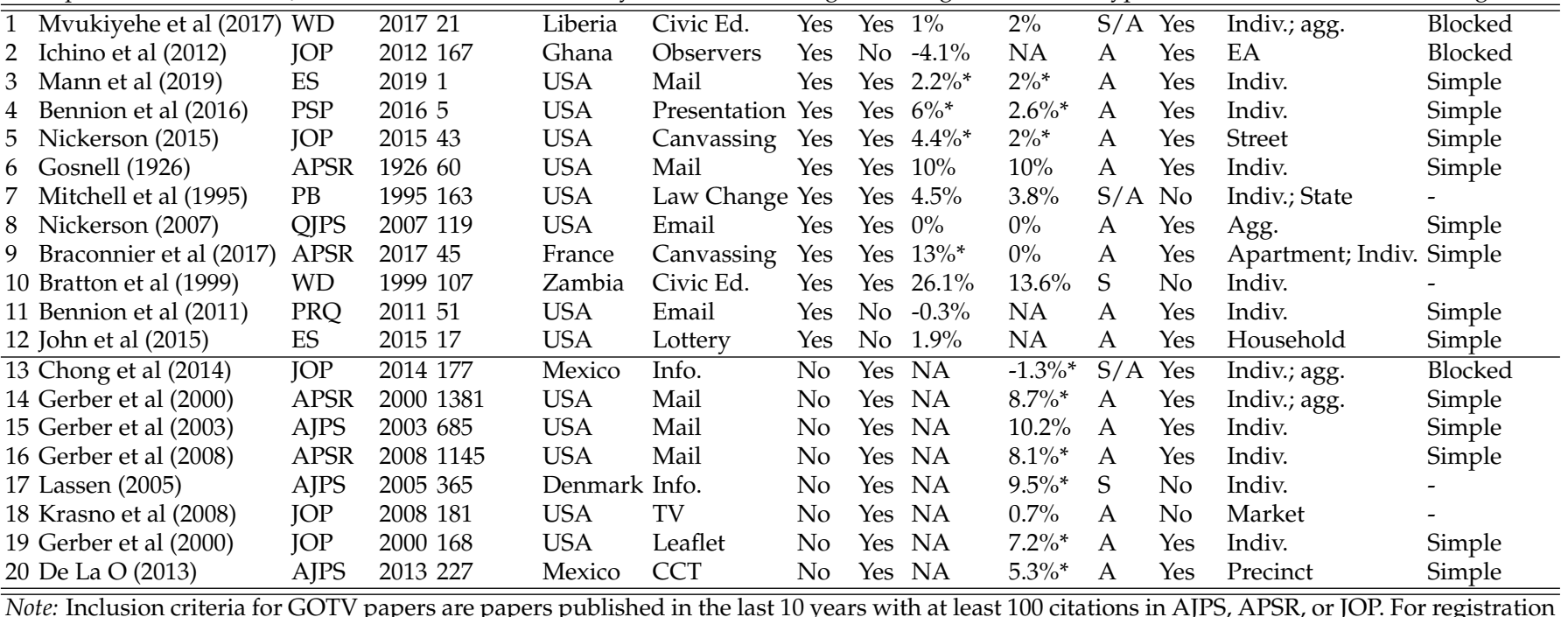
studies (a much smaller literature), we included a wider range of papers with no time restriction, searching for research examining voter registration as an outcome. Citations are taken from Google Scholar, August 7, 2019. Journal: WD = World Development, JOP $=$ Journal of Politics, ES = Electoral Studies, PSP = Political Science and Politics, APSR = American Political Science Review, PB = Political Behavior, QJPS $=$ Quarterly Journal of Political Science, $\mathrm{PRQ}=$ Political Research Quarterly, AJPS = American Journal of Political Science. $*$ means that the estimate is significantly different from zero. Cells without a $*$ were either insignificant or did not report standard errors. Outcome type includes survey (S) and administrative (A). 


\section{K External Validity}

Figures A3 shows the joint distribution of poverty (horizontal axis) and logged population density (vertical axis) for the selected polling stations (white circles) and the full population of polling stations nationally (gray circles). This shows that the population of polling stations that we sampled from largely overlap the distribution of all pollings stations. The areas that do not overlap are urban areas (where things like localization are unlikely to be effective given the relatively close nature of registration opportunities) and pastoralist areas (where localization is problematic given the mobile nature of populations.) 
Figure A3: Comparison National and Sample Distributions

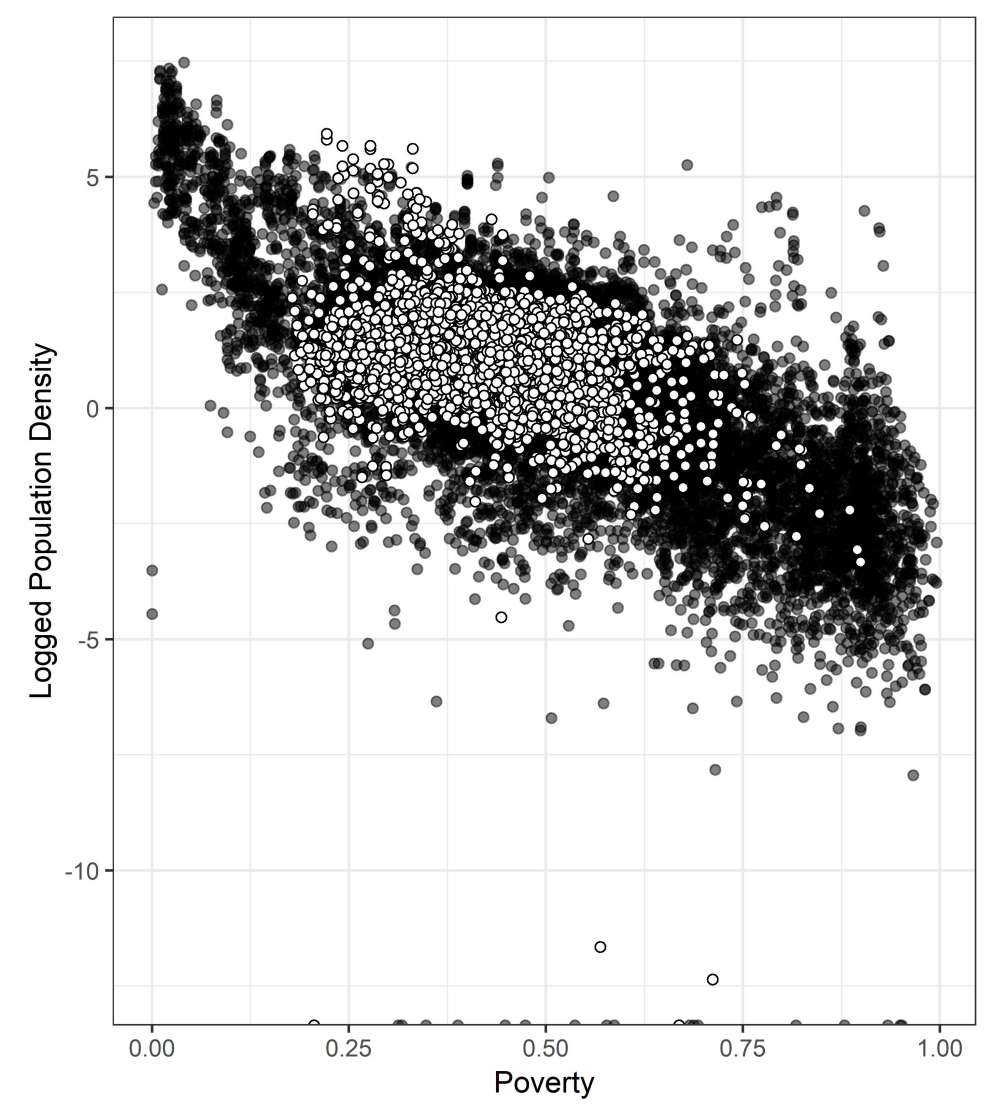

Note: Polling stations in the experimental sample are colored in white; out of sample polling stations for the rest of the country are in black. Given that we do not have data for out-of-sample polling stations on distance to the constituency election office, we present only the joint distribution of poverty and population density here. 


\section{Deviations from Pre-Analysis Plan}

This study was preregistered at the EGAP registry (ID: 20170307AA). The registration took place prior to researcher access to outcome data. In this section, we discuss deviations from the pre-analysis plan, additional analyses not preregistered and items that were preregistered but not undertaken.

First, we note one deviation from the pre-analysis plan.

- Initially, we envisioned the model used in column 2 of Table 2 to be our main specification. Instead, the paper builds further on the model used for column 5 . First, column 5 measures the outcome as the percentage of registered voters at a polling station in 2013, which simplifies interpretation of effect sizes. Second, column

5 collapses the temporal element of our data to the polling station level, which provides more conservative estimates. As we discuss in the text, both sets of results lead to the same substantive conclusions.

Second, the following analyses were not pre-registered:

- Initially, we aimed to understand only the short-term effects of the interventions. However, because the interventions may have very different long run implications we also added Section 4.3, and explore the downstream effects of localization on election day eight months later.

- In Section 4.2 we conduct block-level analyses based on levels of poverty, distance and density. We did not initially pre-register density as a subgroup. This was an omission, because the design is blocked across these three factors.

- The pre-analysis plan did not include a discussion around statistical power. We have added such a discussion, including ex post power calculations, in Appendix D. 
Finally, we list items that we preregistered but did not include in the document.

- We explore differential treatment effects by distance, poverty and density. We also suggested to conduct subgroup analysis by voter characteristics (i.e. gender and age groups), county characteristics (i.e. level of opposition support), and other project design features (i.e. treatment dosage of SMS message, IEBC staff characteristics, day of implementation). In the document we only focus on distance, poverty and density for two reasons. First, the design explicitly blocked for these characteristics. Second, including all of the possible pre-registered analyses in one paper would be impossible, given journal word limits.

-We suggested testing for geographic spillovers; that is, whether the interventions have effects on polling station areas not directly targeted by the IEBC. We have not done so, and explicitly note in our design strategy above how experimental design aims to avoid spillovers.

- We measure the dependent variable in two ways: as the raw counts of registered voters, and as the percentage of registered voters at a polling station in 2013. Initially, we also suggested to measure the outcome as raw counts divided by population density in an 1.5 kilometer radius around the polling station. However, two factors prevent this approach. First, satellite data used to measure population density is not sufficiently accurate to facilitate such an analysis. Second, aggregating spatial population density data to the polling station level requires some reasonable definition of the catchment area of the polling station. Since IEBC does not define - and the law does not require - residency within a particular surveyed catchment area, this approach seemed fraught with ad hoc decisions about how to define catchment areas across regions with massive geographic variation. As a result, we did not proceed with this analysis, as the assumptions and decisions we would have to make seemed 
indefensible, given the reality on the ground. 


\section{References Appendix}

- Bail, Christopher A, Lisa P Argyle, Taylor W Brown, John P Bumpus, Haohan Chen, Fallin Hunzaker, Jaemin Lee, Marcus Mann, Friedolin Merhout, and Alexander Volfovsky. 2018. “Exposure to Opposing Views on Social Media can Increase Political Polarization." Proceedings of the National Academy of Sciences 115 (37): 9216-21.

- Bennion, Elizabeth A., and David W. Nickerson. 2011. "The Cost of Convenience: An Experiment Showing E-Mail Outreach Decreases Voter Registration." Political Research Quarterly 64 (4): 858-69.

- Bennion, Elizabeth A., and David W. Nickerson. 2016. "I Will Register and Vote, if You Teach Me How: A Field Experiment Testing Voter Registration in College Classrooms." PS - Political Science and Politics 49 (4): 867-71.

- Braconnier, Celine, Jean-Yves Dormagen, and Vincent Pons. 2017. “Voter Registration Costs and Disenfranchisement: Experimental Evidence from France." American Political Science Review 111 (3): 584-604.

- Bratton, Michael, Philip Alderfer, Georgia Bowser, and Joseph Temba. 1999. "The Effects of Civic Education on Political Culture: Evidence from Zambia." World Development 27 (5): 807-24.

- Campbell, David E., and Richard G. Niemi. 2016. “Testing Civics: State-Level Civic Education Requirements and Political Knowledge." American Political Science Review 110(3): 495-511.

- Chaudhury, Nazmul, Jeffrey Hammer, Michael Kremer, Karthik Muralidharan, and F Halsey Rogers. 2006. "Missing in Action: Teacher and Health Worker Absence in Developing Countries Background on Education and Health Care Systems in 
Developing Countries." Journal of Economic Perspectives 20 (1): 91-116.

- Dunning, Thad, Guy Grossman, Macartan Humphreys, Susan D Hyde, Craig Mcintosh, Gareth Nellis, Claire L Adida, et al. 2019. “Voter Information Campaigns and Political Accountability: Cumulative Findings from a Preregistered Meta-Analysis of Coordinated Trials." Science Advances 5: 1-11.

- Finkel, Steve E., Christopher A. Sabatini, and Gwendolyn G. Bevis. 2000. “Civic Education, Civil Society, and Political Mistrust in a Developing Democracy: The Case of the Dominican Republic." World Development 28 (11): 1851-74.

- Finkel, Steven E. 2002. "Civic Education and the Mobilization of Political Participation in Developing Democracies." The Journal of Politics 64 (4): 994-1020.

- Finkel, Steven E. 2005. "Civic Education in Post-Apartheid South Africa: Alternative Paths to the Development of Political Knowledge and Democratic Values." Political Psychology 26 (3): 333-64.

- Finkel, Steven E, Jeremy Horowitz, and Reynaldo T Rojo-Mendoza. 2012. “Civic Education and Democratic Backsliding in the Wake of Kenya's Post-2007 Election Violence." The Journal of Politics 74 (1): 52-65.

- Finkel, Steven E., and Amy Erica Smith. 2011. "Civic Education, Political Discussion, and the Social Transmission of Democratic Knowledge and Values in a New Democracy: Kenya 2002." American Journal of Political Science 55 (2): 417-35.

- Gerber, Alan S, and Donald P Green. 2000. "The Effect of a Nonpartisan Get-Outthe-Vote Drive: An Experimental Study of Leafletting." Journal of Politics 62 (3): $846-57$.

- Gerber, Alan S, Donald P Green, and Christopher W Larimer. 2008. “Social Pressure 
and Voter Turnout: Evidence from a Large-Scale Field Experiment." American Political Science Review 102 (1): 33-48.

- Gottlieb, Jessica. 2016. “Greater Expectations: A Field Experiment to Improve Accountability in Mali" American Journal of Political Science 60 (1): 143-57.

- Gosnell, Harold F. 1924. "An Experiment in the Stimulation of Voting." American Political Science Review 20 (4): 869-74.

- Green, Donald P., Peter M. Aronow, Daniel E. Bergan, Pamela Greene, Celia Paris, and Beth I. Weinberger. 2011. "Does Knowledge of Constitutional Principles Increase Support for Civil Liberties? Results from a Randomized Field Experiment." Journal of Politics 73 (2): 463-76.

- Ichino, Nahomi, and Matthias Schundeln. 2012. “Deterring or Displacing Electoral Irregularities? Spillover Effects of Observers in a Randomized Field Experiment in Ghana." The Journal of Politics 74 (01): 292-307.

- John, Peter, Elizabeth MacDonald, and Michael Sanders. 2015. "Targeting Voter Registration with Incentives: A Randomized Controlled Trial of a Lottery in a London Borough." Electoral Studies 40: 170-75.

- Jones, Jessica, Rachel Jones, and Andres Mojica. 2017. "Teacher Allocation and Absenteeism in Kenya, Tanzania, and Uganda: 2015." Georgetown University McCourt School of Public Policy Research Report.

- Krasno, Jonathan S., and Donald P. Green. 2008. “Do Televised Presidential Ads Increase Voter Turnout? Evidence from a Natural Experiment." Journal of Politics 70 (1): $245-61$.

- Langton, Kenneth P., and M. Kent Jennings. 1968. "Political Socialization and the 
High School Civics Curriculum in the United States." American Political Science Review 62(3): 852-67.

- Lassen, David Dreyer. 2005. “The Effect of Information on Voter Turnout: Evidence from a Natural Experiment." American Journal of Political Science 49 (1): 103-18.

- Mann, Christopher B., and Lisa A. Bryant. 2019. "If you Ask, They Will Come (to Register and Vote): Field Experiments with State Election Agencies on Encouraging Voter Registration." Electoral Studies forthcoming: 1-10.

- Miguel, Edward, and Michael Kremer. 2004. "Worms: Identifying Impacts on Education and Health in the Presence of Treatment Externalities." Econometrica 72 (1): 159-217.

- Mitchell, Glenn E., and Christopher Wlezien. 1995. “The Impact Constraints of Legal on Voter of the Composition American Electorate." Political Behavior 17 (2): 179-202.

- Mvukiyehe, Eric, and Cyrus Samii. 2017. “Promoting Democracy in Fragile States: Field Experimental Evidence from Liberia." World Development 95: 254-67.

- Nickerson, David W. 2007. “Does Email Boost Turnout?" Quarterly Journal of Political Science 2 (4): 369-79.

- Nickerson, David W. 2008. “Is Voting Contagious? Evidence from Two Field Experiments." American Political Science Review 102 (1): 49-57.

- Nickerson, David W. 2015. “Do Voter Registration Drives Increase Participation? For Whom and When?" Journal of Politics 77 (1): 88-101.

- Panagopoulos, Costas. 2009. "Partisan and Nonpartisan Message Content and Voter Mobilization Field Experimental Evidence." Political Research Quarterly 62: 70-76.

- Pasek, Josh, Lauren Feldman, Daniel Romer, and Kathleen Hall Jamieson. 2008. 
"Schools as Incubators of Democratic Participation: Building Long-Term Political Efficacy with Civic Education." Applied Developmental Science 12 (1): 26-37.

- Persson, Mikael, and Henrik Oscarsson. 2010. “Did the Egalitarian Reforms of the Swedish Educational System Equalise Levels of Democratic Citizenship?" Scandinavian Political Studies 33 (2): 135-63.

- Pop-Eleches, Cristian, Harsha Thirumurthy, James P Habyarimana, Joshua G Zivin, Markus P Goldstein, Damien de Walque, Leslie MacKeen, et al. 2011. “Mobile Phone Technologies Improve Adherence To Antiretroviral Treatment In a Resource-limited Setting: A Randomized Controlled Trial of Text Message Reminders." AIDS 25 (6): $825-34$.

- Sekhon, Jasjeet S. 2011. “Multivariate and Propensity Score Matching Software with Automated Balance Optimization: The Matching Package for R." Journal of Statistical Software 42 (7): 1-52.

- Sondheimer, Rachel Milstein, and Donald P Green. 2010. “Using Experiments to Estimate the Effects of Education on Voter Turnout." American Journal of Political Science 54 (1): 174-89.

- Slomcyznski, Kazimierz M., and Goldie Shabad. 2003. “Can Support for Democracy and the Market Be Learned in School? A Natural Experiment in Post-Communist Poland." Political Psychology 19 (4): 749-79. 